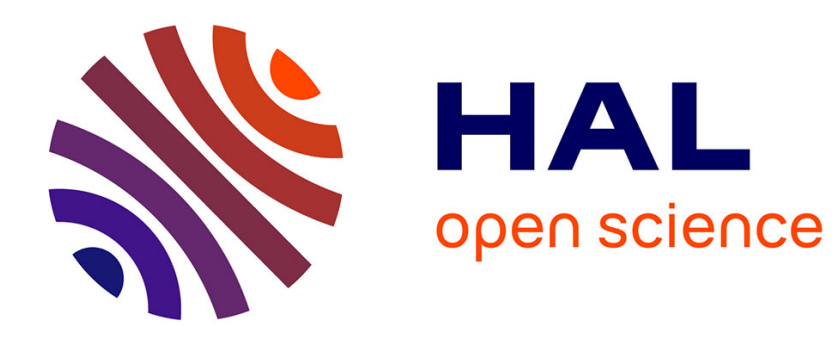

\title{
Le Musée copte du Caire, une utopie architecturale
}

\author{
Julien Auber de Lapierre
}

\section{To cite this version:}

Julien Auber de Lapierre. Le Musée copte du Caire, une utopie architecturale. Annales Islamologiques, 2016. hal-02302435

\section{HAL Id: hal-02302435 \\ https://hal.science/hal-02302435}

Submitted on 1 Oct 2019

HAL is a multi-disciplinary open access archive for the deposit and dissemination of scientific research documents, whether they are published or not. The documents may come from teaching and research institutions in France or abroad, or from public or private research centers.
L'archive ouverte pluridisciplinaire HAL, est destinée au dépôt et à la diffusion de documents scientifiques de niveau recherche, publiés ou non, émanant des établissements d'enseignement et de recherche français ou étrangers, des laboratoires publics ou privés. 


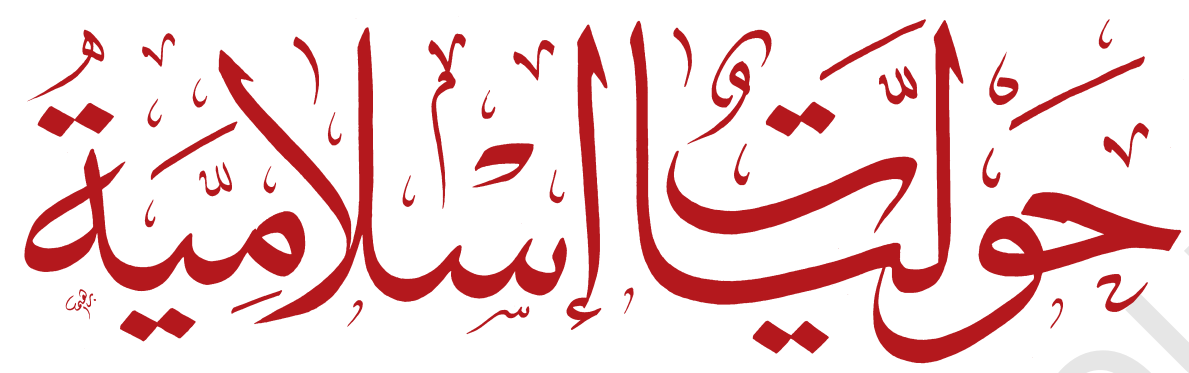

Annales ${ }_{50} \cdot 2016$

islamologiques

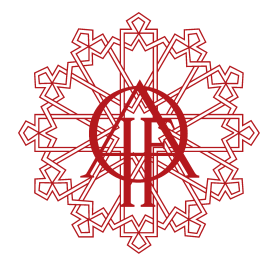

INSTITUT FRANÇAIS D'ARCHÉOLOGIE ORIENTALE AnIs/ $50-2016$ 


\section{Bâtir, exposer, restaurer :} une histoire architecturale de l'Égypte moderne sous la direction de Mercedes Volait

Introduction. Pour une histoire matérielle, savante et pragmatique de la modernité architecturale égyptienne

\section{Dynamiques de la modernité}

Claudine Piaton II Architecture patronale dans l'isthme de Suez (I859-I956)

Adam Mestyan 55 Affairisme dynastique et dandysme au Caire vers 1900.

$\&$ Mercedes Volait Le Club des Princes et la formation d'un quartier du divertissement rue 'Imād al-Dīn

Mohamed Elshahed Io7 Egypt Here and There:

The Architectures and Images of National Exhibitions and Pavilions, I926-1964

\section{Inventions de la tradition}

Dina Ishak BАкноuм 147 Mamluk Minarets in Modern Egypt:

Tracing Restoration Decisions and Interventions

Ezio Godoli 199 Sources idéologiques et iconographiques

des architectures d'inspiration islamique dues à Ernesto Verrucci Bey

Julien Auber de Lapierre 235 Le Musée copte du Caire, une utopie architecturale

\section{Varia}

Yūsuf RĀĠiB 269 Une commande d'articles à Fustat rédigée

dans le dernier tiers du $\mathrm{II}^{\mathrm{e}}$ siècle de l'Islam ou le premier du suivant

Khaled Younes 29I Indecent Clothing and Violence in the Street :

A Third/Ninth-Century Arabic Papyrus

Lahcen DAAÏF 301 L'extension du domaine du șaḩ̣̣̄.

Les procédés d'istibrāğ et d'istidrāk dans les sciences du Hadith

$$
\text { التعاملات القضائية لأهل الذمة في القدس المملوكية } 343 \text { محمد نصر عبد الرحمن }
$$

Ahmad Al-Amer 365 Musiciens et chanteurs dans les Badà' í al-zubūr fì waqā' $i^{\prime}$ al-dubūr d'Ibn Iyās 


\section{Système de translittération}

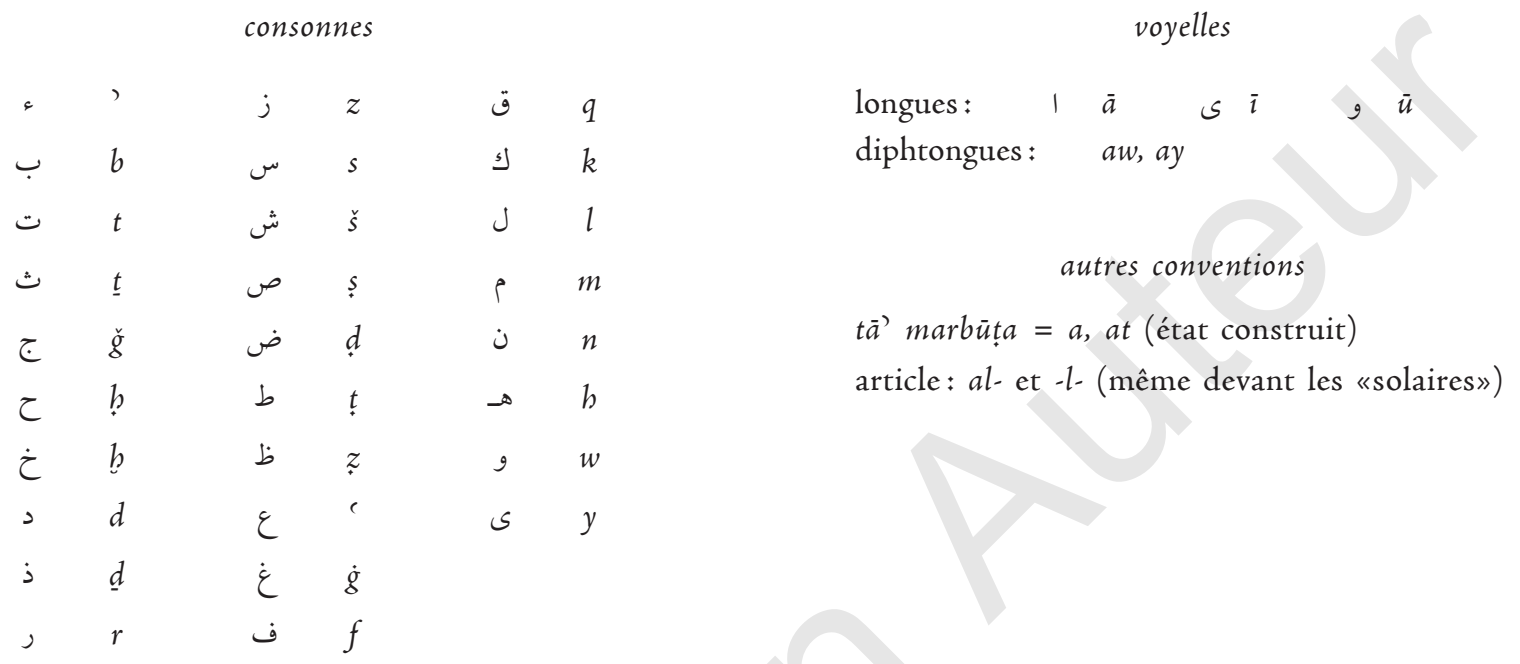

Le système de translittération suivi par les publications arabisantes de l'Ifao est explicité dans le document téléchargeable sur le site de l'institut:

http://www.ifao.egnet.net/publications/publier/normes-ed/ 
JULIEN AUBER DE LAPIERRE*

\section{Le Musée copte du Caire, une utopie architecturale}

\section{+ RÉSUMÉ}

Sous l'impulsion du Comité de conservation des monuments de l'art arabe, en I897, l'architecte Max Herz Bey émit l'idée de création d'un musée destiné aux antiquités chrétiennes. Avec l'appui du patriarche Cyrille V, le choix du site se porta rapidement sur l'ancienne résidence patriarcale de Qașr al-Šam'. Marcus Simaïka Pacha lança en 1908 une souscription permettant de réunir les fonds nécessaires aux derniers travaux de remise en état du bâtiment. L'édifice inauguré en IgIo se révèle rapidement trop petit et des travaux d'agrandissement sont alors projetés. La découverte d'archives inédites a permis de reconsidérer l'histoire du musée mais également le sens que celui-ci a pris dans la première moitié $\mathrm{du} \mathrm{xx}^{\mathrm{e}}$ siècle dans un schéma de construction identitaire de la communauté copte.

Mots-clés: art fatimide, Comité de conservation des monuments de l'art arabe, de Saint-Maurice (Gaston), Hạarat al-Rūm, Lewis (John Frederick), Simaïka Pacha (Marcus Hanna), Herz (Max), mosquée al-Aqmar, al-Mu'allaqa, porche, remploi, résidence patriarcale, Vieux-Caire

* Julien Auber de Lapierre, Doctorant, École pratique des hautes études, auberdl@gmail.com 


\section{+ ABSTRACT}

Under the impulse of the Comite de conservation des monuments de l'art arabe, in 1897 the architect Max Herz Bey expressed the idea of creating a museum for the Christian antiquities. With the support of Patriarch Cyril V, the site selection focused on the old patriarchal residence of Qașr al-Šam'. Marcus Simaika Pasha launched in 1908 a subscription to raise funds for the last restoration works of the building. The museum opened in I9IO, but soon was considered too small and expansion works were projected. The discovery of unpublished archives on the building has allowed reconsidering not only the history of the museum but also the sense that it took in the first half of the 2oth century within an identity construction scheme for the Coptic community.

Keywords: Fatimid art, Comité de conservation des monuments de l'art arabe, de Saint-Maurice (Gaston), Hārat al-Rūm, Lewis (John Frederick), Simaika Pasha (Marcus Hanna), Herz (Max), al-Aqmar mosque, al-Mu'allaqa, porch, reuse, patriarchal residence, Old Cairo

"T'ART arabe a son musée; l'art copte de son côté attend le sien. »C'est par ces mots que Max Herz Bey conclut une lettre à Hussein Fakhry Pacha et lance, le premier, l'idée d'un Musée copte ${ }^{\mathrm{I}}$. La lettre date du 27 décembre 1897 et suit de peu l'extension du champ d'action du Comité de conservation des monuments de l'art arabe aux monuments chrétiens, obtenue en $1896^{2}$. L'architecte en chef du Comité s'y adresse au ministre égyptien des Travaux publics, afin de mettre les « débris de bois sculpté ou planches travaillées, chapiteaux de colonnes ou autres objets encore gisant dans la poussière [... à l'abri de la destruction ». Un Musée copte créé par un Comité de l'art arabe : l'idée même laissait envisager la complexité du chantier. L'art copte était, en cette fin du XIX ${ }^{e}$ siècle, le parent pauvre du riche patrimoine

I. «Lettre lue le 4 janvier 1898 devant l'assemblée du Comité de conservation des monuments de l'art arabe et rapportée au procès-verbal $n^{\circ} 80$ ». Nous remercions très sincèrement Mercedes Volait pour ses relectures attentives et ses judicieux conseils.

2. Proposition effectuée le Io novembre 1894 et rapportée au procès-verbal n ${ }^{\circ} 63$ du Comité de conservation des monuments de l'art arabe: «S.E. Fakhry Pacha pense que le Comité devrait aussi se préoccuper de la conservation des monuments coptes intéressant l'art ou l'histoire. Il propose de se rendre auprès du patriarche pour savoir dans quels termes le Comité pourrait être chargé de l'inspection de ces monuments. Le Comité accepte cette proposition», CCMAA II, p. 60-6I. À la suite de la réalisation «des fouilles dans l'intérieur du Deir el-Màallaka, du côté sud, pour découvrir l'ancienne porte de ce monument» durant l'année I895, il fut décidé par le Comité, le I7 février I896, que «les mesures qu'il y a lieu de prendre pour conserver ce monument ainsi que les autres constructions monumentales existant dans les églises qui dépendent du patriarcat seront décidées par l'architecte du Comité et par un de ses membres, et que tous travaux de conservation et d'entretien des monuments seront surveillés par le Comité », CCMAA I3, p. 33-35. 
égyptien. Après les récits de Claude Fabri de Peiresc ${ }^{3}$ (1580-1637) et de Johann Michael Vansleb 4 (I635-1679) sur cette communauté, l'intérêt scientifique s'était porté ensuite surtout sur les textes en copte, dernier avatar de la langue hiéroglyphique. Auguste Mariette Pacha, initiateur du premier musée en Égypte, n'avait pas le goût des antiquités chrétiennes. Il faut attendre Gaston Maspero, au moment du renouveau de la communauté au Caire, pour en découvrir un témoignage au musée de Boulaq ${ }^{5}$. Cet intérêt ne fit par la suite que s'amplifier avec les travaux de Walter Ewing Crum $^{6}$ et de Josef Strzygowski ${ }^{7}$ et les fouilles d'Albert Gayet ${ }^{8}$, de James Edward Quibell ${ }^{9}$ et de Jean Clédat ${ }^{10}$. C'est face à cet élan scientifique, mais aussi par suite du développement de la revendication identitaire copte, que naquit l'idée d'un musée.

Dès l'envoi de sa lettre, le très actif Max Herz jette les bases de la réalisation du musée en y impliquant le Patriarcat copte orthodoxe et son titulaire, Cyrille V. Il enjoint, par l'intermédiaire de Fakhry Pacha, de «donner ordre à tous les préposés des églises du Caire et de ses faubourgs, de consigner sur [sa] désignation à M. Nakhla Bey el-Barâti tous les objets qui se

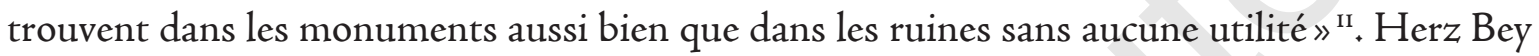
dit avoir rencontré, avant même d'écrire à Fakhry Pacha, le patriarche Cyrille V, et indique que ce dernier « est bien disposé pour ce projet et [qu'] il a chargé Nakhla Bey de choisir une chambre convenable où les antiquités seront déposées ».

\section{La réécriture d'une histoire}

Alors que le Musée arabe a reçu un financement de 45 ooo livres égyptiennes par le khédive Abbas Hilmi II pour la construction d'un nouveau bâtiment dans le centre de la capitale ${ }^{\mathrm{I} 2}$, celui que l'on nomme déjà le «Musée de l'art copte» hérite, après une nouvelle entrevue entre Herz et le patriarche Cyrille V, en I899, "d'une pièce dans l'intérieur du Deir el-Moallaka» que le pape a offerte "pour recueillir les débris de l'art copte ${ }^{13}$. Les relations entre les autorités coptes et le Comité se tendent cependant peu après. Deux lettres du patriarche en date des 20 et 22 mai I899, adressées à Mohammed Faïzi Pacha, président du Comité de conservation des monuments de l'art arabe ${ }^{\mathrm{I4}}$, évoquent des désaccords au sujet de travaux recommandés par le Comité. La seconde lettre détaille les griefs exprimés:

3. Gravit, I938, P. I-22.

4. Vansleb, 1677.

5. Gayet, I889, P. I.

6. Crum, I902.

7. Strzygowski, 1904.

8. Gayet, I902.

9. Quibell, I902, p. 85-88.

Io. Clédat, I904.

I I. CCMAA I5, p. 5.

I2. CCMAA i6, p. 3 .

I3. CCMAA i6, p. 39 .

14. Lettres reproduites dans CCMAA I6, p. 58-60. 
Nous estimons qu'il n'est pas nécessaire de démolir cette partie, et qu'il ne faudrait pas non plus la considérer comme faisant partie de l'église en question [Saint-Chenouté] ; puisqu'il est à remarquer que d'une part ces travaux ne sont pas nécessaires et que d'autre part le but n'est pas d'élargir les emplacements des églises mais plutôt de conserver les monuments dans l'état où ils se trouvent.

Nous sommes d'avis, par conséquent, que ces travaux, pour l'exécution desquels cette somme est allouée, sont inutiles et qu'en les laissant totalement de côté, on pourrait se dispenser en outre de la somme de $150 \mathrm{~L}$. portées sur le devis sous le titre Frais pour la construction d'une nouvelle maison devant servir d'habitation au prêtre, lequel, à notre avis, pourra continuer à se loger dans la maison qu'on voudrait démolir. Ce qui fait 563 L. environ d'économie. [... ]

Nous ne pouvons nullement consentir à l'exécution des travaux de terrassement à l'intérieur de l'église [Abū Sayfayn] et il faudrait se contenter de laisser les choses dans leur état actuel d'ancienneté.

Quant aux autres travaux énumérés dans le devis, nous vous informons que nous ignorons les détails de leur plan de construction et nous ne savons pas non plus si l'exécution de ces travaux peut changer l'état actuel des choses. [...]

Ce court extrait indique clairement les préoccupations et les doutes du prélat, mais aussi son peu d'empressement à l'égard des travaux à réaliser dans la citadelle de Babylone ${ }^{15}$ et dans le monastère Abū Sayfayn proche de la mosquée de 'Amr ibn al-'Āṣ. Il remet en cause les devis effectués, l'intérêt de tels travaux et sous-entend l'impossibilité pour le Patriarcat d'y contribuer financièrement à la hauteur voulue par le Comité. L'ingérence de ce dernier dans les affaires du patriarcat semble particulièrement mal acceptée. Si le procès-verbal annonce que Max Herz doit se rendre auprès de Cyrille V afin de «lui donner toutes les explications relatives aux travaux proposés », la mention suivante du futur musée dans les déclarations du Comité n'intervient néanmoins qu'en $1902^{16}$. La satisfaction qui s'y exprime doit être surtout comprise comme un soulagement de voir s'éloigner les difficultés administratives entre le Comité et le patriarcat. Ce degré d'apaisement correspond aussi à la volonté d'ouverture et

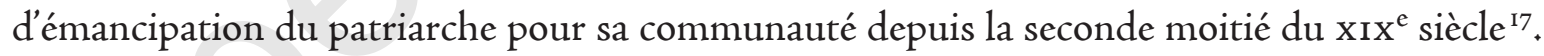
À la suite du règlement du contentieux financier pour les travaux dans les églises du Vieux-Caire, la situation du futur musée évolue à nouveau. Tandis que la mention de l'établissement d'un premier inventaire d'objets était déjà indiquée dans la lettre de Max Herz à Fakhry Pacha en I897, le procès-verbal n ${ }^{\circ}$ I24, par l'intermédiaire de Hanna Bey Bakhoum, stipule «que S.B. le Patriarche copte a fait dresser un inventaire de la plupart des objets antiques qui se

15. Sur la citadelle de Babylone: Sheehan, 2010; Ludwig, Jackson, 2013.

I6. «S.E. Fakhry Pacha annonce au Comité que sur sa proposition S.B. le Patriarche Copte a consenti à recevoir dans un emplacement spécial tous les manuscrits et ouvrages importants coptes qui se trouvent actuellement éparpillés dans les divers couvents et églises d'Égypte », CCMAA I9, procès-verbal n ${ }^{\circ}$ II 2, p. 2 . I7. Voile, 2004, p. II-40. 
trouvent dans les églises et couvents ${ }^{18}$. Max Herz Bey précise alors également au Comité que le prélat a pris soin d' "aménager une pièce dans le palais du Patriarcat pour servir de Musée de l'art copte ${ }^{19}$. Toutefois, une nuance est également annoncée lors de cette séance, à savoir la remarque faite par le patriarche quant à l'impossibilité de déplacer les objets et meubles en « usage constant» dans les édifices religieux ${ }^{20}$.

Le dévouement sans faille de Hussein Fakhry Pacha et de Max Herz Bey pour l'institution d'un musée pour les antiquités chrétiennes n'a été que récemment remis en valeur avec l'appui des sources issues du Comité de conservation des monuments de l'art arabe ${ }^{2 \mathrm{I}}$. Le travail sur l'histoire du Musée copte a été en effet longtemps tributaire des faits relatés par son premier directeur et «fondateur», Marcus Hanna Simaïka Pacha (I864-1944), puis repris par d'autres. Sa nécrologie rédigée par un autre membre du Comité, Hassan Abdel Wahab, mentionne ainsi un discours du prince Mohammed Ali Tewfik louant Simaïka Pacha comme seul et unique créateur du Musée copte et mettant en valeur ses efforts déployés pour l'institution, ainsi que le financement de 500 livres égyptiennes accordé pour la création de la bibliothèque ${ }^{22}$. S'il convient de ne pas ternir l'importance de celui qui fut également président de la Section technique du Comité de conservation des monuments de l’art arabe de 1929 à 1939, il s'agit toutefois de nuancer le rôle qui fut le sien dans la genèse du Musée copte.

Issu d'une famille de magistrats originaires du Vieux-Caire, Marcus Simaïka fit sa carrière dans l'Administration des chemins de fer de l'État. Par la suite, il fut nommé en 1906 membre de l'Assemblée législative et membre du Conseil supérieur de l'enseignement, présidé alors par Saad Pacha Zaghloul ${ }^{23}$; il fit la même année son entrée au Comité de conservation des monuments de l'art arabe ${ }^{24}$. Éminent membre de la communauté copte, Simaïka était membre de son Conseil (al-mağlis al-millī) depuis $1889^{25}$. Toutefois, les relations entretenues avec le patriarcat étaient tendues, puisque le Conseil de communauté ne parvenait pas à être reconnu par le pape Cyrille V, qui refusait l'ingérence de laïcs dans les réformes que menait l'Église. Le vice-président du Conseil, Boutros Pacha Ghali, par ailleurs sous-secrétaire d'État à la Justice dans le gouvernement de Moustafa Pacha Fahmi, et les membres du Conseil appuyèrent alors la décision du khédive Abbas Hilmi II qui, en septembre I892, exila le prélat pendant six mois au monastère al-Baramous ${ }^{26}$. À l'orée de la « renaissance » copte de la fin du xı ${ }^{\mathrm{e}}$ siècle,

I 8. CCMAA 20, p. 44 .

I9. CCMAA 20, p. 44.

20. CCMAA 20, p. 44 .

2 I. Ormos, 2009; Auber de Lapierre, Jeudy, à paraître.

22. BSAC I2, i949, p. I6I.

23. Simaika, 20II, p. 35-49.

24. La proposition d'intégrer Marcus Simaikka, après la disparition de Nakhla Bey Youssef el-Barâti, comme membre du Comité de conservation des monuments de l'art arabe lors de la séance du I2 décembre 1905 revient à Hussein Fakhry Pacha, CCMAA 22, p. I04. En vertu de la décision du khédive Abbas Hilmi II, il est nommé membre du Comité le i3 février I906: CCMAA 23, p. 9.

25. Simaika, 20II, p. 62 .

26. Guirguis, van Doorn-Harder, 20II, p. 9I. 
entamée sous Cyrille IV ${ }^{27}$, la communauté fut particulièrement meurtrie par cette mésaventure et soulagée par le retour du patriarche au Caire, à la suite d'une pétition que Simaïka avait refusé de signer ${ }^{28}$.

Personnalité ayant eu très jeune la volonté de prendre part à l'avenir de sa communautée Marcus Simaïka parcourt tôt - les archives conservées par son petit-fils, Samir Mahfouz Simaika, fils de Youssef Simaïka Bey, le révèlent - les ouvrages sur la richesse du patrimoine historique chrétien d'Égypte, ceux d'Alfred J. Butler, co-fondateur avec Somers Clarke, Bernhard Moritz et Max Herz de la Société pour l'histoire de l'antiquité copte en 1903, ou ceux d'Albert Gayet ${ }^{30}$. Marqué par les pertes irrémédiables et les destructions volontaires ${ }^{31}$, devenu une personnalité influente et un ami proche de Max Herz ${ }^{32}$, Marcus Simaïka devait logiquement être intégré au Comité de conservation des monuments de l'art arabe.

Son rôle dans la fondation du Musée copte est toutefois à nuancer, par rapport à ce qui a été souvent écrit. En effet, la nécrologie mentionnée plus haut, mais aussi les différents historiques du musée, s'appuient principalement sur les guides rédigés par Simaïka lui-même et publiés entre 1930 et $1938^{33}$, et sur ses mémoires, dont le manuscrit non publié est conservé par son petit-fils, qui en a tiré une biographie en $20 \mathrm{II}^{34}$. Cette insistance qu'éprouve Simaïka, de son vivant, à mentionner son rôle de fondateur du Musée copte, conduit à en interroger le bien-fondé. Dans une conférence présentée en 1992, l'historien Donald Malcolm Reid expose le rôle important qui lui revient pour la construction de l'identité copte ${ }^{35}$. Il évoque la naissance mythique du Musée copte que Simaïka relate dans ses mémoires en faisant valoir le sauvetage qu'il fit de vaisselles d'argent et de plats de reliures achetés au patriarche avant qu'ils soient fondus ${ }^{36}$. Il explore également le rôle social et identitaire joué par celui qui devint

27. Reid, 1995, p. 312-314; Reiss, I998; Guirguis, van Doorn-Harder, 20II, p. 73-78.

28. Simaïka, Mémoires, p. 86-87.

29. Il est élu membre du mağlis millì à l'âge de 25 ans.

30. Butler I884 et Gayet I899. Marcus Simaïka Pacha dédie d'ailleurs son guide sommaire du Musée copte à Alfred Butler dont la première publication lui a inspiré «l'idée d'obtenir du Gouvernement de placer les anciennes églises coptes sous le contrôle du Comité de Conservation des Monuments de l'Art Arabe, les sauvant ainsi d'une destruction certaine, et de fonder le Musée copte».

3I. Nous ne mentionnons ici que la destruction des icônes réalisées sans doute par le peintre Yuhannā al-Armanī à la fin du Xviri ${ }^{e}$ siècle pour la cathédrale Saint-Marc et détruites, dans un élan de recherche de modernité, sous le patriarche Cyrille IV: Butler, I884, p. 96 ; Auber de Lapierre, 2015, p. 3I.

32. Les archives conservées par Samir Mahfouz Simaika mentionnent « un très bon ami».

33. Simaïka, 1930-1932; 1937 et 1938.

34. Simaika, 20II.

35. Reid, I995, P. 3II-335.

36. "One day in the winter of 1908 Murqus Simaika, vice president of the Coptic Community Council (Al-Majlis al-Milli), called on Patriarch Kyrillus V and found him watching as a silversmith weighed out old silver gospel covers and church vessels to be melted down for reworking. They bore i4th and isth century inscriptions in Coptic and Arabic. Simaika offered to raise the L.E. I80 market value of the bullion if these objects would be saved in a storeroom as a start toward a museum. The Patriarch agreed, and the Coptic Museum was born », Reid, 1995, p. 3II d'après Simaïka, Mémoires, p. 42-43. Cet épisode est également mentionné dans Simaika, 20II, p. 9 I et 95. 
le vice-président du Conseil de communauté après la nomination de Boutros Pacha Ghali comme premier ministre en 1908. Il marque l'importance que prend au début du $\mathrm{xx}^{\mathrm{e}}$ siècle le Musée copte comme ultime lien dans l'histoire de l'Égypte entre le Musée gréco-romain d'Alexandrie et le Musée arabe du Caire ${ }^{37}$.

Or, dans ses mémoires, rédigées bien des années plus tard, Marcus Simaïka Pacha passe sous silence nombre de protagonistes à l'origine du Musée copte. Simaïka suscita certes, par son entregent et sa position au sein de la communauté, un véritable élan pour finaliser le projet lancé par Max Herz, et surtout permettre un financement plus faste que les subsides offerts par le Comité de conservation des monuments de l'art arabe. Le premier directeur de l'institution prit l'initiative de lancer une souscription en janvier 1908 afin de pourvoir au financement de la structure, dont le parrain et premier signataire n'était autre que le prince et futur sultan Hussein $\mathrm{Kamal}^{38}$. Suivent ensuite des noms familiers tels que le Premier ministre, Boutros Pacha Ghali (ıo livres égyptiennes), le ministre Fakhry Pacha (2 livres égyptiennes), l'architecte en chef du Comité, Max Herz Pacha, (I livre égyptienne). La liste a la grande particularité de regrouper les membres égyptiens et britanniques du gouvernement mais également des membres de la société civile et religieuse, aussi bien chrétiens que musulmans, et de différentes nationalités.

L'idée était insufflée depuis I897, la collection constituée, le financement assuré, les locaux trouvés : il ne restait plus qu'à inaugurer le musée.

\section{Un bâtiment à inventer}

Après une première visite en avril I908 du ministre des Travaux publics, Hussein Fakhry Pacha, accompagné de Hanna Bey Bakhoum et de Marcus Simaïka Bey, la véritable inauguration du bâtiment se tint le I4 mars I9Io en présence du patriarche Cyrille V, du ministre Fakhry Pacha, de Herz Pacha, Boinet Pacha, et Simaïka Bey. Les travaux étaient pourtant loin d'être terminés, et le musée demeurait fermé au public ${ }^{39}$.

La question du bâtiment s'est posée très tôt, puisqu'elle apparaît déjà dans la lettre de Max Herz de $1897^{40}$. Le choix du Dayr al-Mu'allaqa étant établi, on l'a dit, depuis $1899^{41}$, il est précisé en 1903 qu'il s'agit d'une pièce du palais du Patriarcat ${ }^{42}$. Un bref rappel historique est ici nécessaire. Si l'on se réfère à l'évolution des résidences du patriarche de la communauté copte orthodoxe, le titre de ce dernier rappelle que son Siège originel se situait à Alexandrie avant son déplacement au Caire à l'époque fatimide sous le patriarcat de Cyrille II (IO78-IO92) ${ }^{43}$.

37. Reid, 1995, p. 324.

38. L'exemplaire original de la souscription avec les signatures et montants donnés est conservé dans les collections de la famille Simaika et reproduit dans Simaika, 20II, p. 92.

39. CCMAA 25, p. 22-23.

40. CCMAA I5, p. 4-6.

4I. ССMAA I6, p. 39.

42. CCMAA 20, p. 44.

43. Coquin, I991, p. 1912-I913; Martin, I998, p. 46; den Heijer, 2002, p. 83-97. 
Par suite de ce transfert, le Siège patriarcal sétablit en l'église al-Mu'allaqa. L'Histoire des Patriarches mentionne en effet la construction d'une maison en haut de l'église sous Michel IV (I092-IIO2). L'existence d'une cellule ( $\kappa \varepsilon \lambda \lambda$ íov) dans l'église est également évoquée dans le récit attribué à Abū Ṣālih al-Armanī sous le patriarcat de Marc III (II66-II89) ${ }^{44}$. Lusage désigne d'ailleurs toujours sous ce terme la chapelle supérieure de la partie méridionale de l'édifice, où se trouve un sanctuaire dédié à saint Marc ${ }^{45}$. De cette occupation découle sans doute la construction d'un bâtiment plus ample en bordure de l'église mais qui reste difficile à identifier dans l'historiographie, le palais patriarcal étant systématiquement nommé «cellule» dans les textes des différentes périodes ${ }^{46}$.

Un plan de I9I2, année de la visite du musée par le prince Jean-Georges de Saxe ${ }^{47}$, découvert dans les Archives du Comité de conservation des monuments de l'art arabe par István Ormos et conservé au Markaz tasğìl al-ātār al-islāmiyya wa-l-qibțiyya (Centre d'enregistrement des monuments islamiques et coptes) du ministère égyptien des Antiquités situé à la Citadelle du Caire, montre ainsi la plus ancienne attestation de l'organisation projetée des bâtiments peu de temps après l'inauguration du Musée copte ${ }^{48}$. Ce plan, approuvé par Max Herz - il porte sa signature, ce qui montre sa constante implication - présente un couloir d'accès ouvert depuis la rue Mār Ğirğis, depuis une porte proche de celle donnant accès à la cour et aux escaliers menant à l'église al-Mu'allaqa. Ce couloir débouche sur une cour puis sur un bâtiment intitulé «école el-Moallaka », correspondant sans doute à l'ancienne résidence, transformée et donnée par le patriarche pour y déposer les «débris de l'art copte». Au-delà de ce bâtiment que l'on peut identifier comme étant la structure primitive de la partie occidentale de l'aile dite «ancienne» du Musée copte ${ }^{49}$, se déploie un projet organisé autour d'une cour intérieure. Cette dernière est mentionnée sur le plan de I9I2 comme étant un jardin divisé en trois par la présence de deux murs. Le document indique également le projet d'édification d'une structure carrée, surmontée d'une coupole à l'extrémité orientale, et d'un escalier extérieur. Si ce plan ne donne pas davantage d'indications sur l'organisation des salles du musée, il conserve la trace de logements, de passages et de jardins au-delà de la structure muséale dans la partie occidentale, et de terrains vagues vers le nord.

De nombreux projets d'embellissement de ce bâtiment se succédèrent afin de lui donner "un style en harmonie avec les différentes collections qu'il renferme "50. Parmi ces études, István Ormos a pu mettre en évidence un dessin de Max Herz pour un projet de façade du Musée copte (fig. I). Les Archives du Comité de conservation des monuments de l'art arabe

44. CME, p. 23, 27 et 32 ; Coquin, I974, p. 70 et I99I, p. I912-1913.

45. Loon, 2013, p. 80 .

46. Coquin, I99I, p. I912-1913.

47. Saxe, I9I4, p. 6-9.

48. Ormos, 2009, p. 343: «Relevé fait de l'annexe de l'église el-Moallaka pour le projet du Musée copte» par M. Muller Ing, Inv, Monuments coptes $n^{\circ} 55$, plan $n^{\circ} 518$, 15 juin 1912.

49. Le rez-de-chaussée correspond à la bibliothèque du musée et l'étage aux salles actuellement utilisées pour la présentation des icônes.

50. Simaïka, I937, p. 2 . 
conservées à la Citadelle du Caire ont livré tout un ensemble de dessins et de plans inédits illustrant la profusion des intentions architecturales voulues pour le musée. À la suite de ces réflexions, Achille Patricolo, successeur de Max Herz Pacha à partir de 1914, mettait en avant les transformations nécessaires au déploiement des collections ${ }^{51}$ :

Le Service avait étudié en 1913 un projet de façade de l'aile est du Musée en même temps qu'un autre ayant pour but l'établissement d'un accès convenable à l'intérieur de la porte sud de qasr ach-Cham' sur lequel s'appuie une partie du Musée.

À l'occasion des travaux de dégagement de cette porte [... et à la demande de S.E. Simaïka pacha, le Service étudia en 1916 un nouveau projet comprenant la construction d'un portique (takhtaboche) au rez-de-chaussée de l'aile est pour l'exposition des stèles, ainsi que la construction d'une nouvelle aile sur le côté nord du jardin. Ce projet a été mis en exécution grâce aux fonds que S.E. Simaïka pacha avait obtenus par souscription des personnalités de la communauté copte.

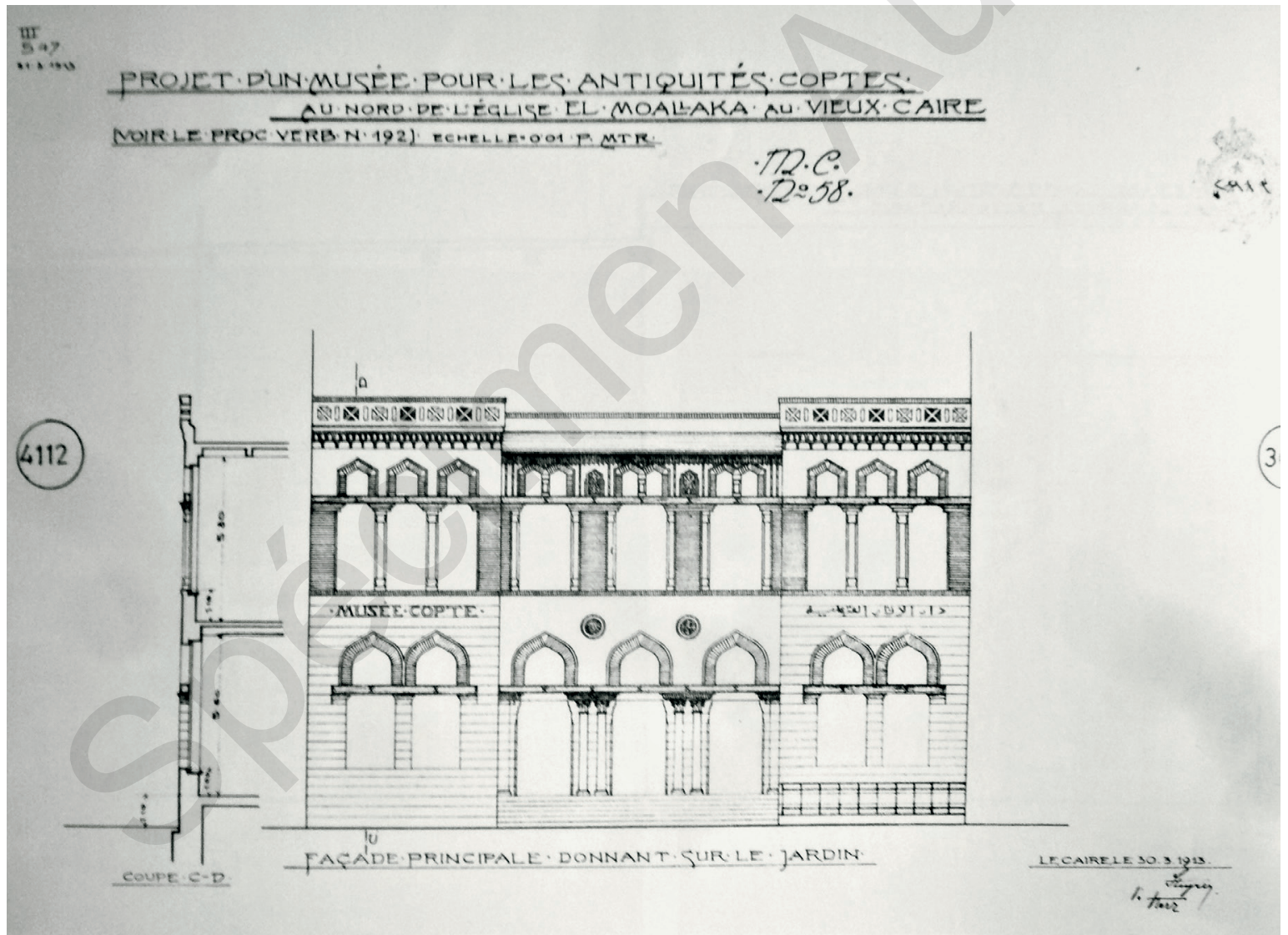

Fig. I * Projet d'un musée pour les antiquités coptes au nord de l'église el-Moallaka au Vieux-Caire », dessin de M. Steyrer, visé par Max Herz pacha. Archives du ministère des Antiquités (fig. 244, Ormos, 2009). 
Le prince de Saxe avait jugé de son côté le classement des œuvres incertain, les salles trop petites, évoquant même des conditions peu optimales ${ }^{52}$. Conscient de ces défauts, le Comité de conservation des monuments de l'art arabe avait décidé de charger Max Herz de diriger les projets d'agrandissement du bâtiment le I4 mars $1912^{53}$. Les dessins furent soumis et approuvés par le Comité le 6 mai I9I3, sans pour autant être suivis d'effets ${ }^{54}$. Parmi ces projets figure celui de la façade principale et sa coupe donnant sur le jardin, réalisé par M. Steyrer et publié par István Ormos ${ }^{55}$. L'élévation proposée figure un corps central de bâtiment pourvu de trois ouvertures et flanqué de deux ailes. Il ne présente qu'un seul étage percé de grandes ouvertures et un toit en terrasse. D'un style sobre, la partie supérieure des baies et des portes présente pourtant déjà la particularité d'accueillir les formes de carènes apparues sous les Fatimides ${ }^{56}$. Un autre plan présente quant à lui l'organisation de vastes salles au rez-de-chaussée, derrière la façade évoquée, conçues autour d'un grand escalier central ${ }^{57}$. L'étage est décrit sur une autre feuille; l'idée de l'escalier structurant l'espace y est reprise ${ }^{58}$.

L'ensemble de ces projets ne trouva pourtant aucune réalisation concrète. Ils restèrent lettre morte à la suite de l'expulsion d'Égypte de Max Herz Pacha, en sa qualité de sujet hongrois, au début de la Première Guerre mondiale. Achille Patricolo, son adjoint au Comité, fut nommé inspecteur chargé des travaux techniques du Comité, lequel ne souhaitait ni n'avait les ressources nécessaires pour remplacer Herz au poste d'architecte en chef ${ }^{59}$. Patricolo dut assumer la lourde tâche laissée par son prédécesseur d'édifier de nouveaux bâtiments pour un musée dont les collections ne cessaient de croître. Il dressa un ensemble de projets entre I9I6 et 1922, secondé par les architectes Gaston(e) Rossi et Giuseppe Tavarelli, qui débutaient alors leur carrière égyptienne ${ }^{60}$. Conservés dans les Archives du Comité de conservation des monuments de l'art arabe, ces dessins présentent de nombreux croquis, élévations et plans reprenant l'idée déjà évoquée en 1912 d'un bâtiment quadrangulaire avec cour intérieure. Partant des salles originales de la résidence patriarcale situées au sud, le long de l'église de la Vierge Marie al-Mu'allaqa et surplombant l'antique accès à la forteresse romaine de Babylone, un bâtiment formant un L fut adjoint à l'est. Les salles septentrionales et occidentales furent construites et achevées en 1920 lors de la visite du sultan Fouad. Venu inaugurer le nouvel ensemble, le sultan manifesta d'ailleurs son intérêt pour l'institution en lançant l'idée d'une souscription qui permit de réunir pas moins de 2000 livres égyptiennes. C'est également à la

52. "Aber ideal ist der Zustand des Museums in keiner Weise », Saxe, 1914, p. 7.

53. CCMAA 29, p. 34-35.

54. CCMAA 30, p. 63-64.

55. «Projet d'un musée pour les Antiquités coptes au nord de l'église el-Moallaka au Vieux-Caire, Façade principale donnant sur le jardin », par M. Steyrer, Inv. Monuments coptes n ${ }^{\circ} 58$, plan n ${ }^{\circ}$ 547, 30 mars I913. 56. Behrens-Abouseif, 1989, p. IO.

57. «Projet d'un musée pour les Antiquités coptes au nord de l'église el-Moallaka au Vieux-Caire », visé par Max Herz, Inv. Monuments coptes $n^{\circ} 57$, plan $n^{\circ} 545$, 3I mars I913.

58. «Projet d'un musée pour les Antiquités coptes au nord de l'église el-Moallaka au Vieux-Caire coupe A-B », par M. Steyrer, plan n ${ }^{\circ} 546$, 31 mars 1913.

59. Ormos, 2009, p. IOI.

60. Sur ces architectes, voir Godoli, Giacomelli, 2005, p. 309-310 et 326-327. 
suite de cette visite que le souverain émit le souhait que le musée, de fondation privée, rejoigne l'administration royale, et que le patriarche le cède à la Couronne ${ }^{61}$. Marcus Simaïka Pacha, face au courroux du patriarche et ne voulant pas déplaire à Sa Majesté, tenta en 1924 d'établir un compromis dont les différents points furent soumis à celui qui était devenu le roi Fouad $\mathrm{I}^{\mathrm{er}}$ :

- Un décret royal doit confirmer que le site et les ouvres appartiennent à l'Église copte et que ces dernières ne pourront être déménagées.

- Le musée continue d'être dirigé par un comité de notables coptes présidé par le patriarche. Le comité est composé de douze membres, quatre choisis par le patriarche et huit laïcs élus par le Conseil de communauté copte tous les cinq ans, suivant le procès-verbal du Comité de conservation des monuments de l'art arabe du 6 mai igi3.

- Le ministre des Finances supervise les dépenses et les recettes du musée qui sont accordées par le gouvernement.

- Le musée est nommé Monument national par le ministre des Finances ou le ministre des Waqfs.

Face aux exigences de la communauté copte, le roi refusa de recevoir Simaïka. Régulièrement exclus de l'identité nationale que se construisait alors l'Égypte en lien avec les nombreuses montées nationalistes, les coptes opèrent dans ces années-là un «dédoublement de mémoire », comme l'écrit Laure Guirguis, allant du regroupement communautaire à la revendication pharaonique $^{62}$. Il faut attendre 1930 et la visite du roi des Belges Albert Ir au Musée copte pour que les tensions s'estompent. Grâce à l'intervention du nouveau directeur général des Beaux-Arts, l'historien de l'art français Louis Hautecœur, et suivant sans doute le vœu de Simaïka, le Musée copte devient une institution d'État et son directeur est nommé à son poste à vie par décret royal de janvier 193I. Bien que Simaïka soit accusé de trahison par la communauté copte, il s'agit là d'un tournant pour le musée qui reçoit dès lors de nouvelles dotations permettant d'acquérir des terrains au nord allant jusqu'à l'église Saints-Serge-et-Bacchus et laissant entrevoir l'arrivée de nombreuses œuvres majeures qui étaient jusque-là présentées au Musée égyptien de Qaṣr al-Nīl ${ }^{63}$.

Le bâtiment, tel qu'il se présentait au moment de la visite du sultan Fouad en I920, correspondait au vaste ensemble quadrangulaire mentionné précédemment et que l'on nomme aujourd'hui «ancienne aile». Les collections étaient organisées ainsi :

- Rez-de-chaussée

+ Salle I: Bibliothèque

+ Salle 2: Objets en pierre

+ Salle 7 : Icônes et peintures

6I. Simaika, 20II, p. I03-I05; Auber de Lapierre, Jeudy, à paraître.

62. Guirguis, 2012, p. 69.

63. Pierre Lacau, directeur du Service des antiquités de l'Égypte, s'étant farouchement opposé à ce transfert, il ne fut opéré qu'après son remplacement par le chanoine Étienne Drioton. Le déménagement fut décidé en 1939, mais les caisses furent entreposées dans le Sérapéum de Memphis et n'arrivèrent au Musée copte qu'au lendemain de la Seconde Guerre mondiale: Gabra, Eaton-Krauss, 2006, p. 4. 
- Premier étage

+ Salle 3: Métaux

+ Salle 4 : Textiles

+ Salle 5: Verres et céramiques

+ Salle 6 : Bois

Les élévations réalisées sous la direction d'Achille Patricolo sont présentées par Simaïka comme étant dans un «style copte ${ }^{64}$. Il mentionne très probablement et plus spécialement ici le porche abritant le nouvel accès au musée et décoré de «six colonnes en marbre, surmontées de chapiteaux en forme de corbeille avec oiseaux et croix, reproduits d'après le $\mathrm{N}^{\circ} 3507$, exposé dans la salle $4{ }^{65}$ (fig. 2). Les références à ce style sont nombreuses et les dessins inédits conservés aux Archives de la Citadelle révèlent l'inventivité des architectes en matière d'élévations envisagées pour le bâtiment. Elles révèlent également la volonté du premier directeur du musée de célébrer le glorieux passé de la communauté chrétienne en Égypte.

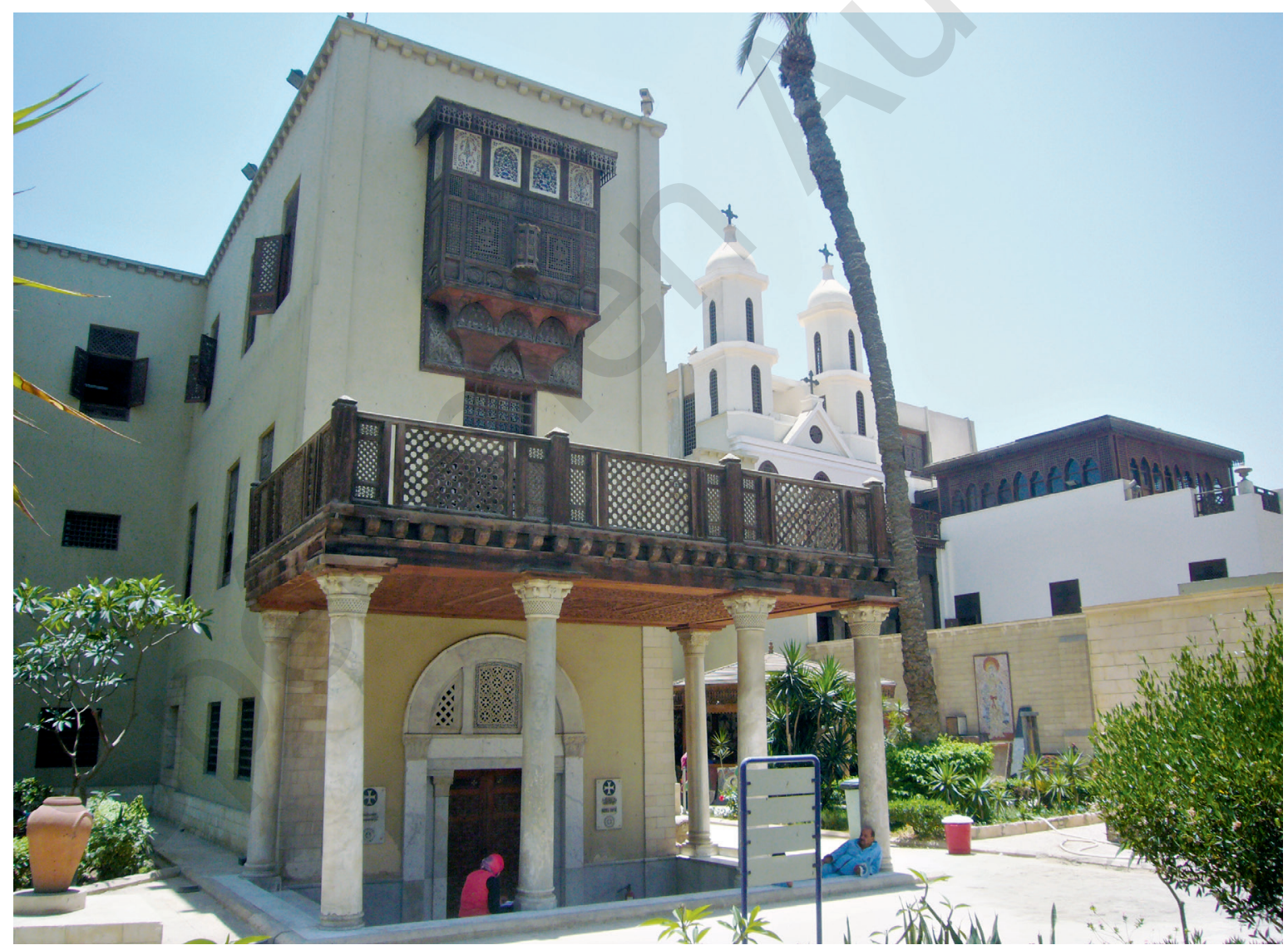

Fig. 2. Porche d'entrée du Musée copte.

(C) Julien Auber de Lapierre, avec l'aimable autorisation du Musée copte.

64. «Construit spécialement à leur intention dans le style copte sous la surveillance de feu Herz Pacha et M.A. Patricolo, Architecte en chef du Comité de conservation des monuments de l'art arabe qui en élaborèrent les plans... », Simaïka, Notes historiques, p. 4-5.

65. Simaïka, 1937, p. 2 . 
Les baies sont ainsi réalisées sous forme d'arcatures ${ }^{66}$. Le projet de structure surmonté d'une coupole néo-fatimide se concrétise à l'est. Cette partie de l'édifice est pourvue d'un escalier extérieur en angle droit partant du jardin et permettant de rejoindre le premier étage ${ }^{67}$. Gaston Rossi prépare également des dessins pour la réalisation des colonnettes de marbre, dont les abaques, ornés de croix, viennent animer les façades ${ }^{68}$, tandis que l'on projette déjà l'installation de moucharabiehs pour les grandes baies de l'étage ${ }^{69}$. Le plan d'ensemble des façades intérieures nord et ouest, réalisé par Tavarelli en 19ı8, permet de considérer les souhaits des architectes ${ }^{70}$. Le plan du jardin intérieur est également réalisé par Rossi en 1920 avec l'organisation des différentes allées et l'installation d'une fontaine au centre ${ }^{71}$.

Toute l'organisation de ces bâtiments est remise en cause par l'acquisition ultérieure de terrains plus au nord. Les expropriations débutent dans les années 1920 et sont rapportées dans un plan dressé en 1924 et conservé à la Citadelle ${ }^{72}$. Y sont mentionnées trois maisons appartenant originellement à Wasef al-Shobokshy, Shenouda al-Sarrif et Manqarios Bishara. Un quatrième lot est indiqué comme étant vide. Ces acquisitions changent notablement l'orientation du musée, puisqu'un jardin extérieur peut se développer en direction de la grosse tour méridionale de la citadelle de Babylone et de l'église grecque Saint-Georges. Les nouveaux apports financiers permettent également de construire une nouvelle salle au-delà du quadrilatère originel joint à l'aile nord.

Construit durant les années I920, ce bâtiment inauguré en 1929 est dévolu à la présentation des icônes et des fresques, ce qui permet au musée d'être désormais pourvu de vingt-cinq salles (fig. 3). Utilisée aujourd'hui comme entrée principale du Musée copte, cette structure présente une façade directement inspirée de celle de la mosquée al-Aqmar (fig. 4). Cet édifice, qui ne «mérite pas de description particulière » selon Émile Prisse d'Avennes, offre pourtant un bel et rare exemple d'architecture de l'époque fatimide ${ }^{73}$. Situé au nord de l'emplacement du grand palais, il semble avoir été fondé en II25 par le vizir du calife Manșūr al-Āmir bi-Aḥkām Allāh, al-Ma'mūn al-Bațā'iḥīi ${ }^{74}$. Outre son plan atypique, la façade de cette petite mosquée révèle de nombreuses originalités issues de traditions antérieures, comme les panneaux sculptés en partie supérieure, que l’on retrouve dans le décor de la mosquée al-Hākim (990-I003).

66. «Nouveau takhtaboche, fenêtre du ${ }^{\text {er }}$ étage et châssis des fenêtres », visé par Achille Patricolo, Inv. Monuments coptes $\mathrm{n}^{\circ} 237$, non daté.

67. Inv. Monuments coptes $\mathrm{n}^{\text {os }} 63,68,69$ et 70 .

68. Inv. Monuments coptes ${ }^{\text {os }} 267$ et 268. Les chapiteaux sont inspirés de ceux découverts à Fustat: M.C. 3I. 69. Parmi les nombreux exemples, nous pouvons citer "Nouvelle moucharabieh sur la façade Nord Est», Inv. Monuments coptes n ${ }^{\circ}$ 249, par Giuseppe Tavarelli, visé par Achille Patricolo, I5 novembre 1920. Celui-ci a la particularité de présenter une note manuscrite de Marcus Simaïka Pacha en français: «Approuvé. À exécuter le plus vite possible. M. H. Simaïka.»

70. Inv. Monuments coptes $\mathrm{n}^{\circ} 23 \mathrm{I}$.

7I. Inv. Monuments coptes $n^{\circ} 246$. Le plan $n^{\circ} 2883$ (Inv. Monuments coptes $n^{\circ} 72$ ), daté de 1917, montre un dessin de Rossi pour une fontaine. Aucun élément ne permet de dire si celle-ci fut réalisée.

72. Plan sans numéro d'inventaire.

73. Prisse d'Avennes, I877, p. 99; Warner, 2005, p. 93-94.

74. Behrens-Abouseif, 1989, p. 72-73; O’Kane, 2016, p. 28-3I. 


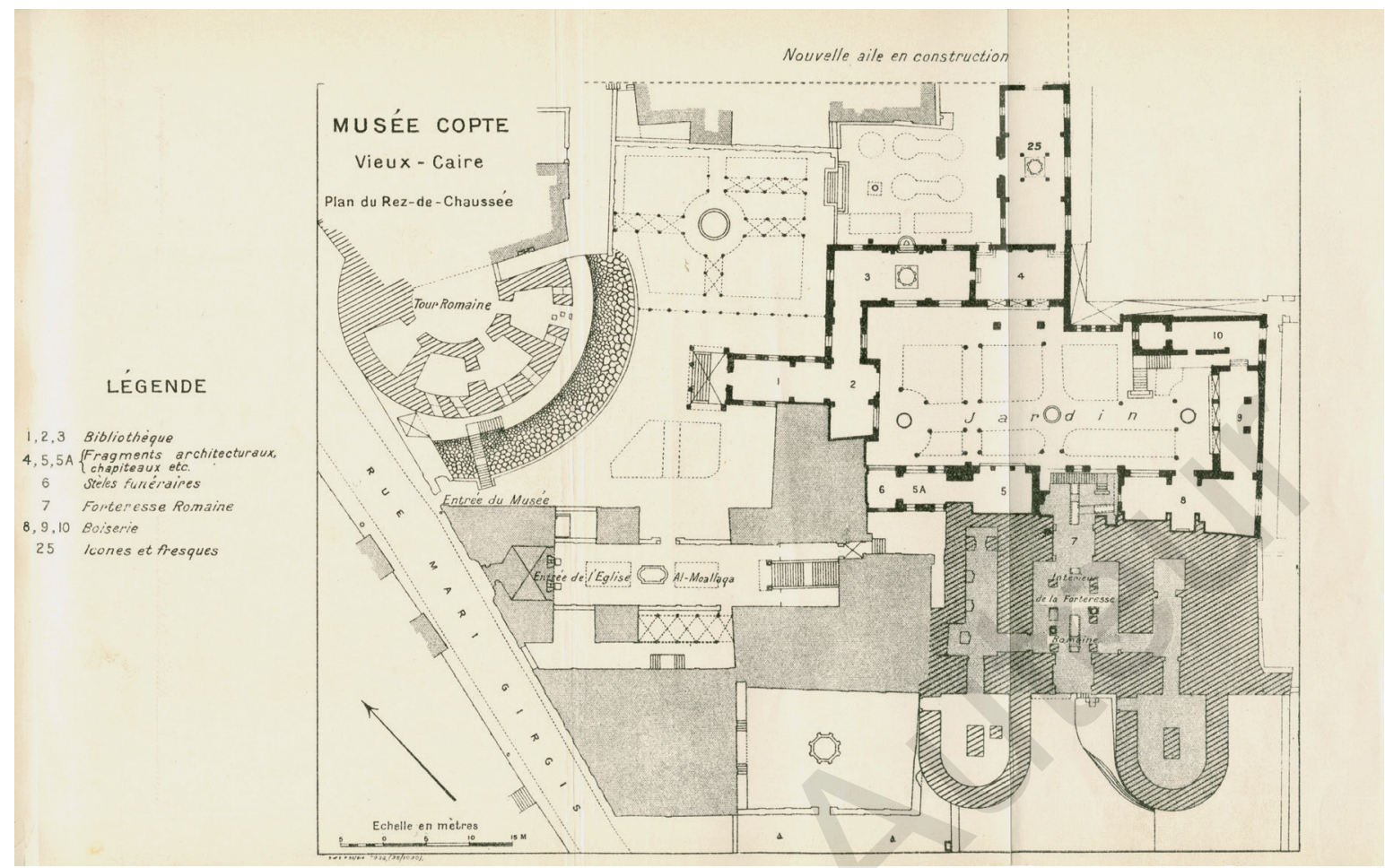

Fig. 3. Plan du rez-de-chaussée du Musée copte en 1937.

(D’après Simaïka, I937, planche hors-texte, entre p. xir et p. I).

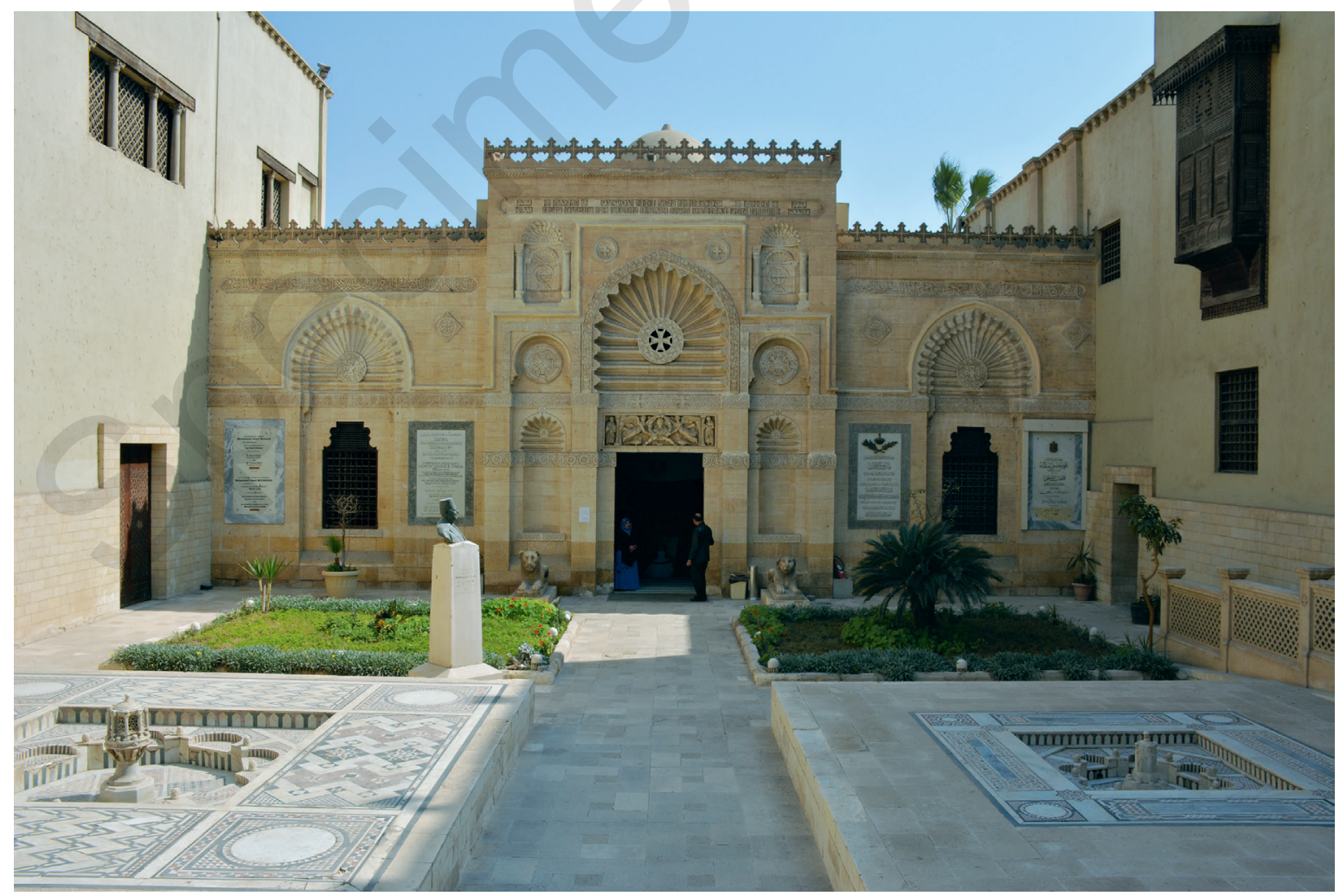

Fig. 4. Façade néo-fatimide du Musée copte.

(C) Julien Auber de Lapierre, avec l'aimable autorisation du Musée copte. 
Son état actuel résulte de travaux conduits par le Comité de conservation des monuments de l'art arabe, qui expropria Moustapha Bey el-Meligby en conséquence du plan de restitution du monument dressé par Max Herz en $1903^{75}$ (fig + 5). La partie droite de la façade, qui semble manquer puisqu'il fut imaginé que le portail devait être au centre, fut alors restituée en se basant sur la partie gauche conservée. La structure est donc tripartite, marquée par une partie centrale en légère saillie. Le portail est surmonté d'une arche en carène à motifs radians, au centre de laquelle est sculpté un médaillon. Ce dernier porte le nom du prophète Muhammad sur le pourtour et le nom de son gendre 'Alī au centre, marquant l'attachement à l'islam chiite des Fatimides. De part et d'autre de la porte, deux niches, dont la partie supérieure reprend le motif de l'arche centrale à nervures, sont surmontées de muqarnas dans des structures carrées. La partie gauche de la façade et la partie droite restituée présentent une grande niche centrée toujours surmontée de l'arche en carène à motifs radians. Un ensemble de frises épigraphiques en écriture coufique, de médaillons, de losanges décorés de plantes et de niches dans lesquelles sont sculptées des lampes suspendues et des coquilles, viennent compléter cet ensemble. Si les motifs végétaux ont été interprétés par Caroline Williams comme des symboles faisant référence aux deux fils de Fāṭima et ' Ali, Hasan et Husayn ${ }^{76}$, ils se retrouvent aussi à de très nombreuses reprises dans l'art chrétien au même titre que les lampes suspendues et les coquilles. Ce dernier motif, évoquant dans la mythologie grecque et romaine l'idée de naissance et de source de vie, est repris dans l'art chrétien, à la suite de l'Édit de Milan en 313, puis dans l'art islamique sans véritablement changer de sens ${ }^{77}$.

Dans ce schéma de construction identitaire de la communauté copte en cette première moitié de $\mathrm{xx}^{\mathrm{e}}$ siècle, le caractère matriciel - et par essence antérieur - de l'art chrétien sur l'art islamique explique la volonté de Marcus Simaïka Pacha de reprendre la façade d'une mosquée fatimide. Pour lui, elle s'inscrit comme le témoignage de l'architecture religieuse copte disparue. Il réaffirme ainsi par cette nouvelle salle du musée la prééminence de l'art copte et son influence sur tout ce qui lui a succédé ${ }^{78}$. Dans son esprit, «la plupart des musulmans descendent des coptes et tous les "musulmans éclairés" sont d'accord $\gg 79$. Le type de baies réalisées pour l'«ancienne aile», ainsi que la coupole, montraient déjà la volonté de donner à l'ensemble du bâtiment une architecture copte telle que transmise par l'architecture fatimide, selon l'esprit de Simaïka ${ }^{80}$ (fig. 6). Si la façade de ce nouveau bâtiment s'inspire donc directement de

75. CCMAA 6, p. II2-I13. Plan Sect. I, no 519, 13 mai 1903. Ormos, 2002, p. 131. Les travaux de dégagement de la façade ont pu être effectués suite au versement, en I906, de I 057 livres égyptiennes pour expropriation: CCMAA 23, p. 76. La restitution de la partie sud n'a été entreprise, quant à elle, que dans les années I990: Warner, 2005, p. 94 .

76. Williams, $1983, \mathrm{p}, 37$.

77. Boutros, I992, p. 8I-87; Rutschowscaya, I998, p. 289-303.

78. «S.E. Morcos Simaika Pacha, directeur du musée copte, en a conclu que la façade d'el-Akmar devait reproduire les façades d'églises coptes et s'en est inspiré pour construire la salle des icônes de son musée », Hautecœur, Wiet, 1932, p. 248, note 2.

79. Simaïka, 1938, p. XI.

80. Sur la postérité de l'architecture néo-fatimide: Sanders, 2008, p. I26-I29. 


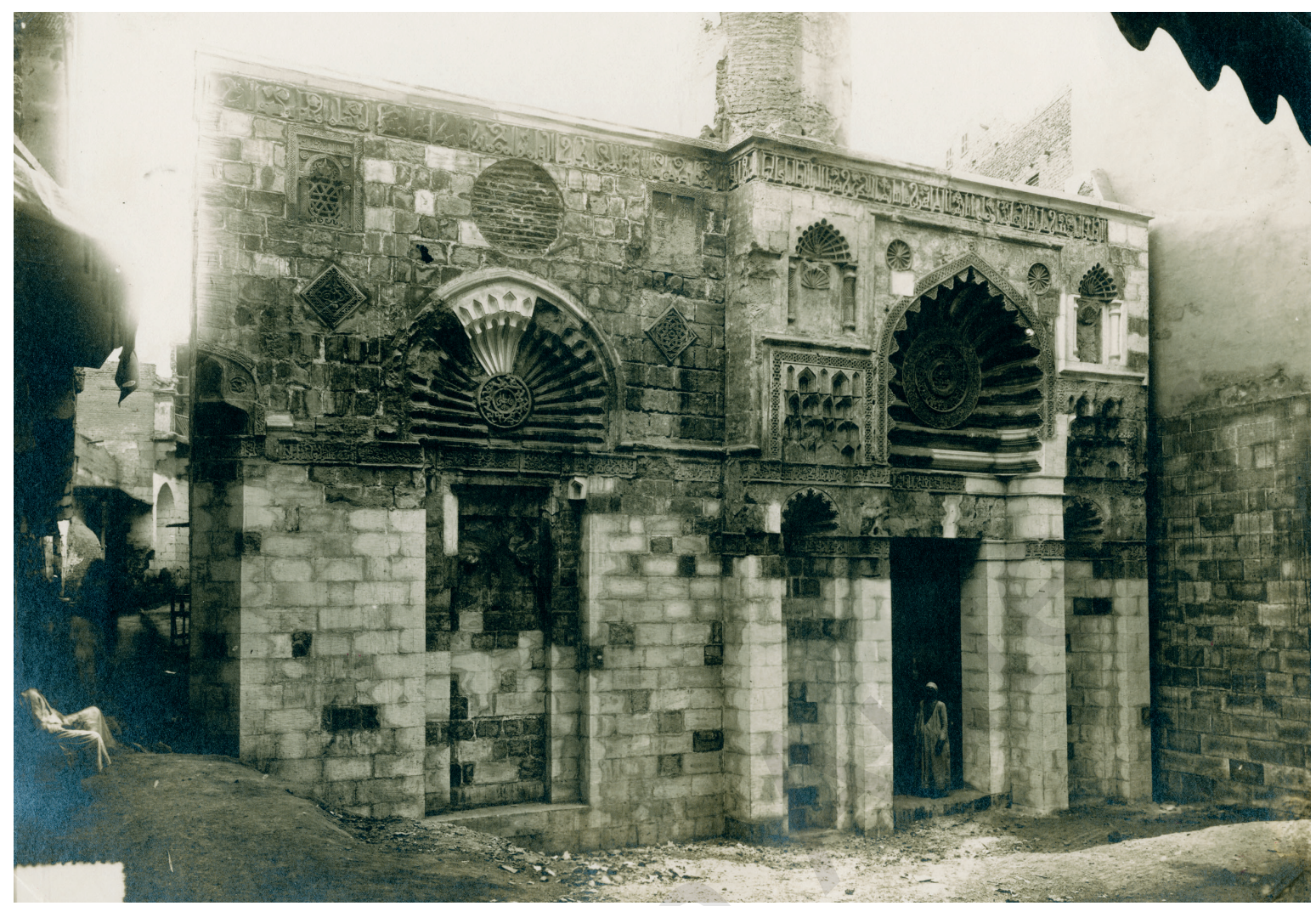

Fig. 5. Keppel Archibald Cameron Creswell, Façade de la mosquée al-Aqmar. (C) Rare Books and Special Collections Library, The American University in Cairo.

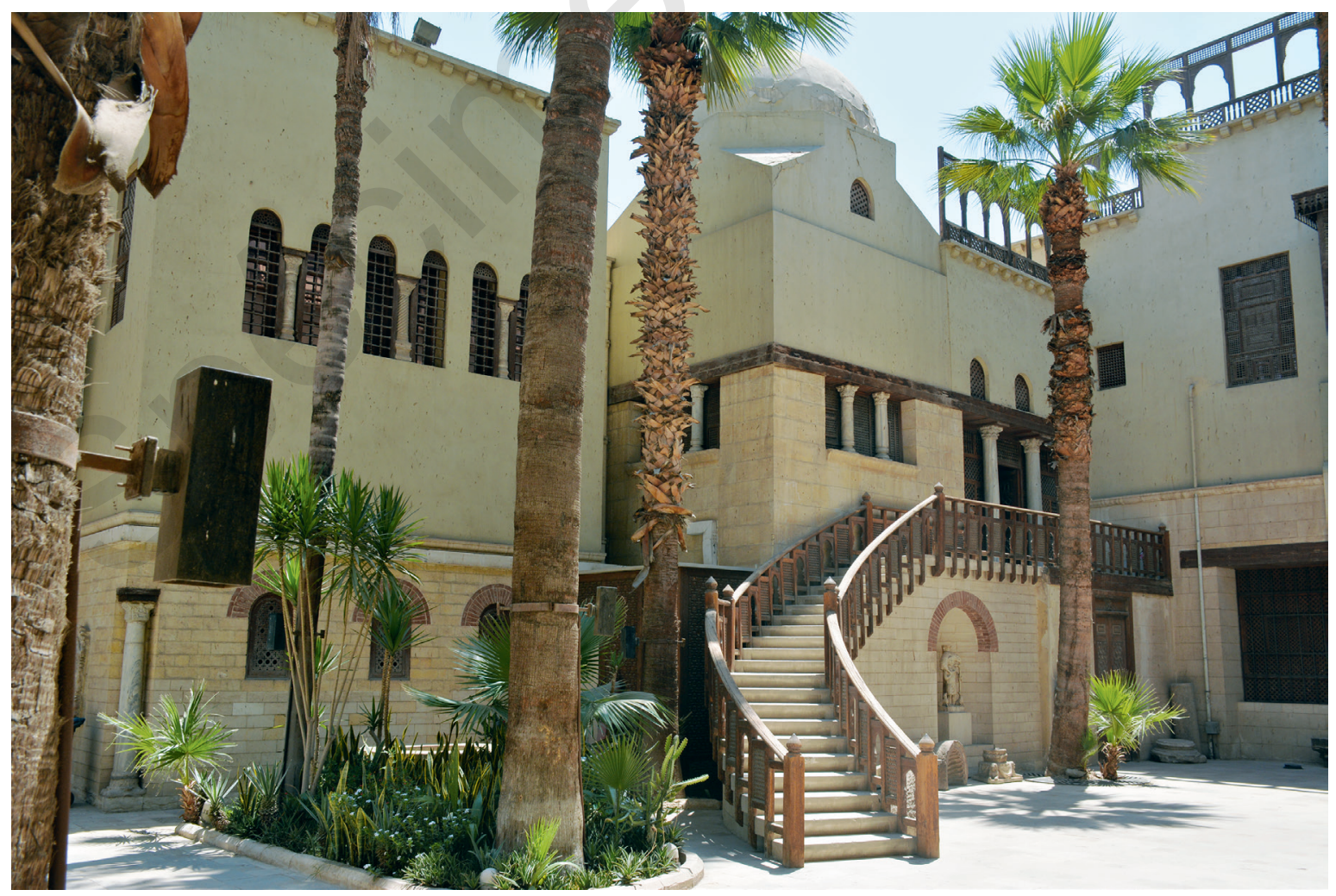

Fig. 6. Cour intérieure de l'«ancienne aile», vue de l'escalier et de la coupole. (C) Julien Auber de Lapierre, avec l'aimable autorisation du Musée copte. 
la mosquée al-Aqmar, cette nouvelle salle demeure toutefois peu documentée et aucun nom d'architecte ne peut lui être associé ${ }^{81}$. Il semble que Simaïka Pacha se soit beaucoup impliqué dans le choix de cette façade et dans sa transposition aux standards coptes.

Si l'ensemble de la structure correspond en effet à la façade de la mosquée fatimide avec la restitution de la partie droite par le Comité -, la plupart des motifs ont été remplacés par un vocabulaire iconographique chrétien. La partie centrale est percée d'une grande porte surmontée d'une arche en carène à motifs radians comme sur le modèle original, mais c'est un médaillon orné d'une croix pattée entourée de rinceaux de vignes qui trouve sa place au centre (fig. 7). Deux niches sont placées toujours de part et d'autre de la porte, mais ce sont de grands médaillons cruciferes entourés de lauriers qui remplacent les muqarnas. Le motif de la croix remplace également les ornements de plantes du décor original, les lampes suspendues et la balustrade couronnant la façade. De même, les deux grandes niches sur les côtés sont surmontées d'arches en carène au centre desquelles sont placés des médaillons ornés de croix pattées entourées de rinceaux de vignes. Des éléments de végétaux stylisés et des frises épigraphiques en copte et en arabe viennent compléter cet ensemble.

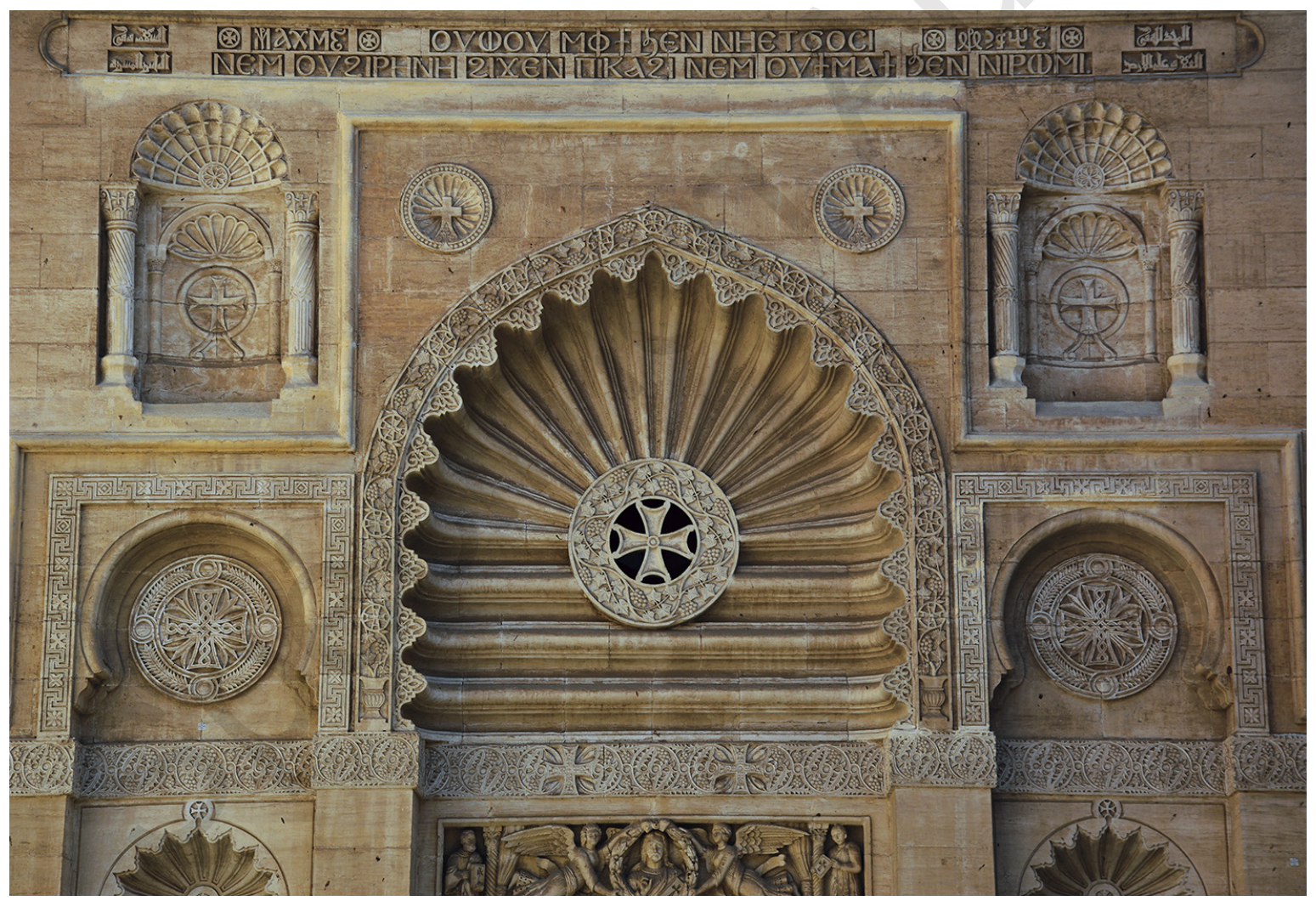

Fig. 7. Façade néo-fatimide du Musée copte (détail).

(C) Julien Auber de Lapierre, avec l'aimable autorisation du Musée copte.

8I. Aucun plan ou élévation ne sont conservés dans les Archives du Comité de conservation des monuments de l'art arabe. M. Atef Naguib, directeur du Musée copte, a créé un département des Archives en 2015 dans lequel un conservateur va être prochainement chargé du récolement des documents ayant trait à l'histoire de l'établissement. 
Parmi tous ces éléments permettant de comprendre la réaffirmation d'une identité copte d'après une référence islamique, il convient de s'attarder sur la véritable nouveauté introduite sur cette façade, à savoir le linteau placé au-dessus de la porte néo-mamelouke (fig. 8). Le décor de celui-ci est issu d'un bas-relief de vantail de porte qui « fut découverte par le fondateur du Musée lors de la restauration de l'église Sitt Barbara au Vieux-Caire ${ }^{82}$. Le contexte de la découverte de cette porte à deux vantaux, considérée par Achille Patricolo comme «la plus intéressante» lors des travaux de restauration de l'église Sitt Barbāra, est à relativiser puisque le compte-rendu du Comité y précise très clairement que «par une heureuse coïncidence, S.E. Simaïka Pacha se trouvait présent à la découverte», ce qui démontre à nouveau le goût de la réécriture $\mathrm{du}$ premier directeur du Musée copte ${ }^{83}$. Longtemps conservée murée, cette porte est sculptée d'un côté de rinceaux de vignes et de l'autre de registres animés. Parmi ceux-ci, la partie supérieure du vantail droit présente une imago clipeata figurant le Christ bénissant de la main droite et tenant les Saintes Écritures de la gauche (fig. 9). Ce buste est porté par deux personnages ailés vêtus de tuniques flottantes. Sous ces deux êtres, deux oiseaux sont figurés sur la ligne de sol. De part et d'autre de cette image centrale sont sculptées deux colonnes torses auxquelles sont noués des rideaux. Aux extrémités de la composition, deux hommes vêtus d'une tunique et portant un ouvrage au plat de reliure crucifère se tournent vers la figure centrale. Il s'agit peut-être de Pierre et Paul. Cette porte, découverte en 1918 et datée des VII ${ }^{\mathrm{e}}$-VIII ${ }^{\mathrm{e}}$ siècles, fait partie des pièces majeures conservées au Musée copte. Son décor fut ainsi scrupuleusement copié et sculpté comme linteau de porte pour la nouvelle façade. Marcus Simaïka Pacha y tenait particulièrement et elle fut sans doute choisie par ses soins pour réaffirmer l'antériorité de l'architecture religieuse copte.

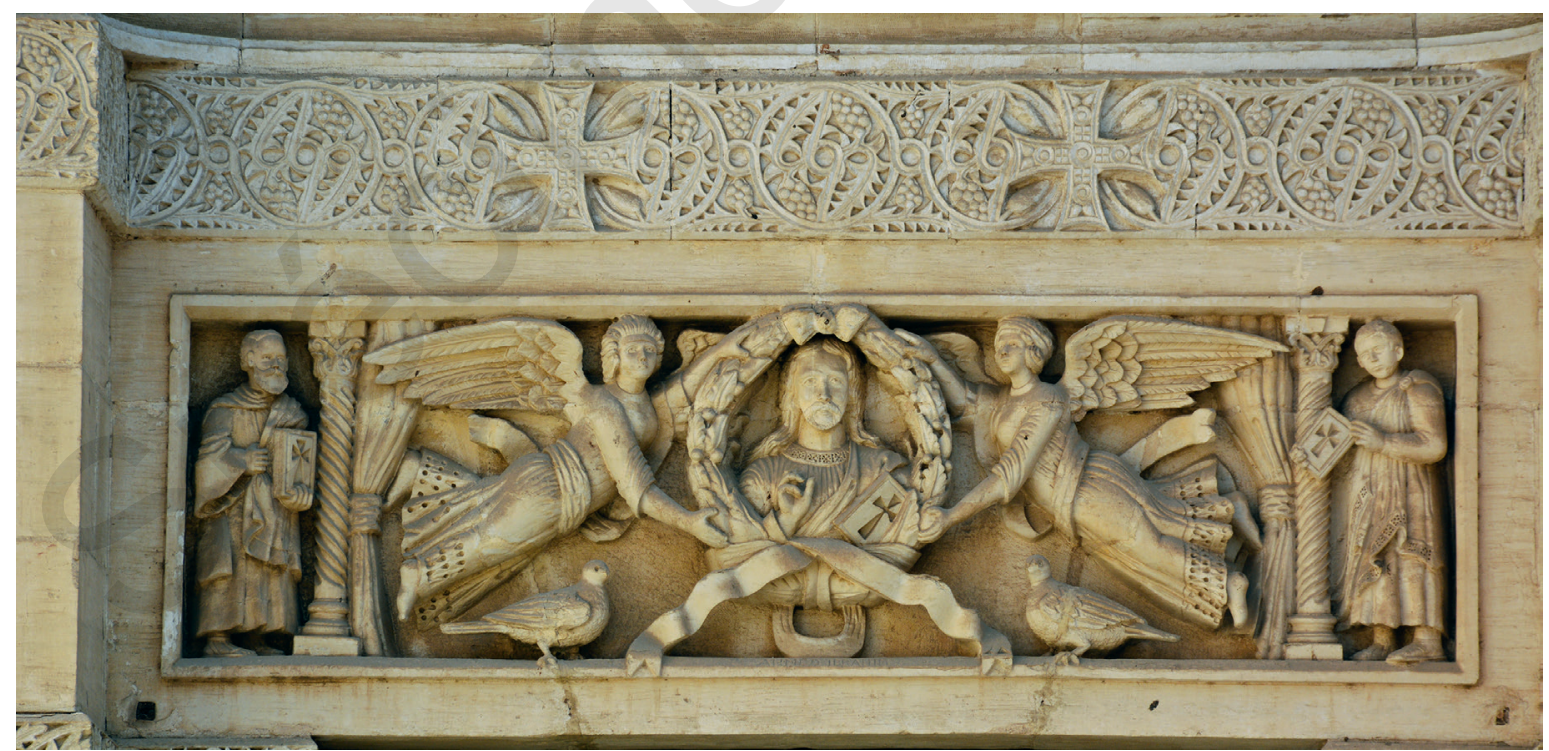

Fig. 8. Façade néo-fatimide du Musée copte (détail du linteau central).

(C) Julien Auber de Lapierre, avec l'aimable autorisation du Musée copte.

82. Simaïka, 1937, p. 28.

83. CCMAA 32, p. 197-198. 


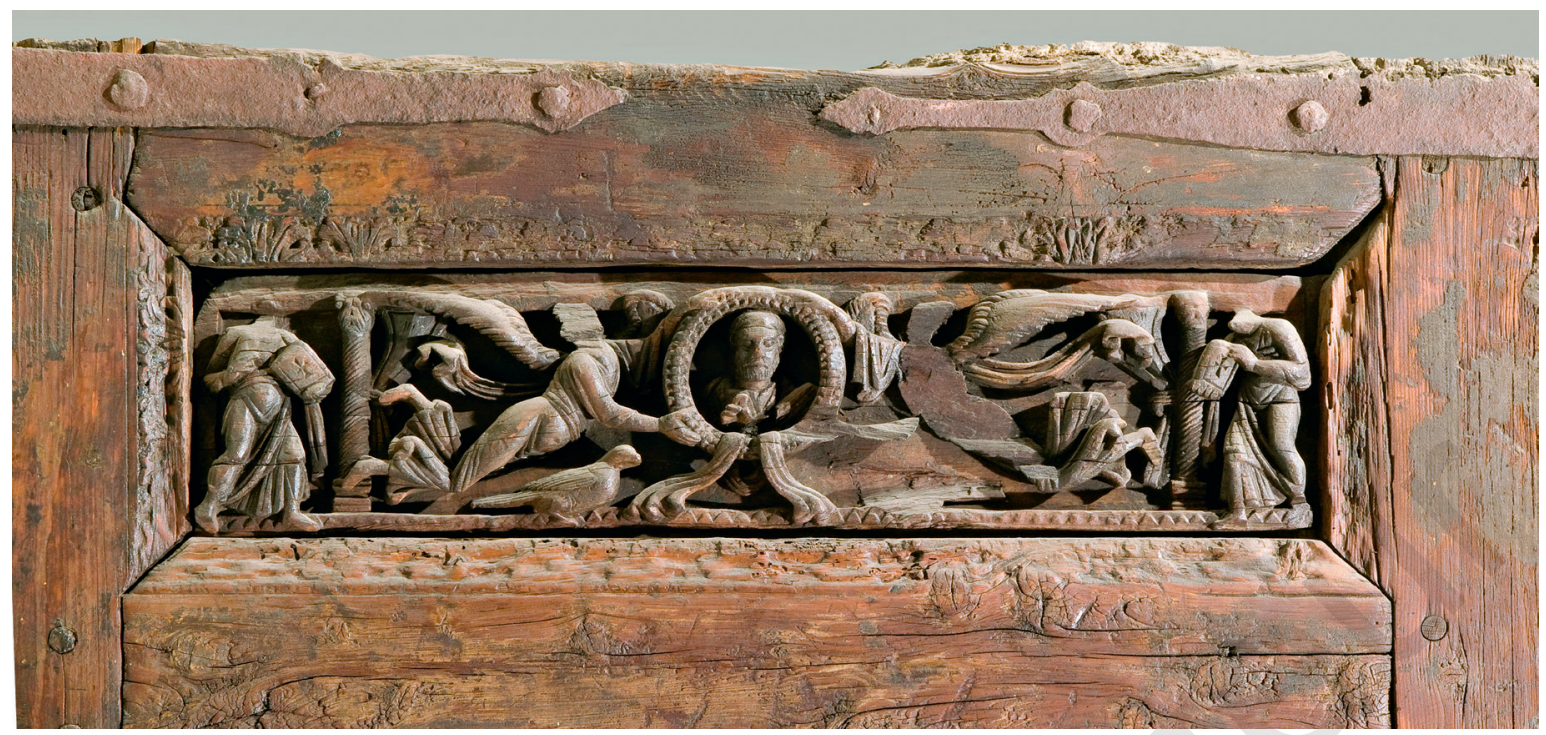

Fig. 9+ Porte à deux vantaux (détail du décor du vantail droit), M.C+738, Le Caire, Musée copte. (C) A. Lecler, Ifao.

\section{Sources et ressources}

À l'avant de ce bâtiment néo-fatimide abritant à l'époque de Simaïka les icônes, ainsi qu'à l'intérieur de la salle même, se trouvent trois fasqiyya-s (bassin dans lequel retombe à l'origine un jet d'eau) que l'on peut dater stylistiquement de l'époque mamelouke (fig. Io et II) ${ }^{84}$. Il existe en effet dans l'architecture du Musée copte de nombreuses pièces de remploi qui sont à la source même de la variété architecturale du bâtiment, mais aussi sa raison d'exister.

Marcus Simaïka Pacha mentionne dans ses mémoires que des éléments issus des ruines du Palais patriarcal de Ḥārat al-Rūm, et notamment des fasqiyya-s, furent réutilisés pour le Musée copte ${ }^{85}$ (fig. 12). Simaïka Pacha fait ici référence à la résidence que les patriarches se firent édifier et utilisèrent depuis Matthieu IV (I660-I675) jusque Marc VIII (I797-I8IO) dans le sud du Caire historique, près de Bāb Zuwayla. Le récent article de Magdi Guirguis consacré à la résidence du patriarche et plus précisément à quatre documents de l'administration des Waqfs permet de faire un point sur ce bâtiment aujourd'hui disparu ${ }^{86}$. Le premier document, daté de 877/1472 et conservé dans les Archives du patriarcat copte orthodoxe ${ }^{87}$, mentionne un bâtiment situé à Hārat al-Rūm près d'une église. La façade est en brique avec trois portes à un vantail. L'une d'elles donne sur un escalier menant à l'église. Le document, dans lequel la description du bâtiment est particulièrement précise, insiste sur le fait que le patriarche doit restaurer le

84. Cette datation est également indiquée par Marcus Simaïka : Simaïka, I930, p. 33.

85. Simaika, 20II, p. 95-97.

86. Guirguis, 2015, p. 19I-216.

87. Inv. D 428. 


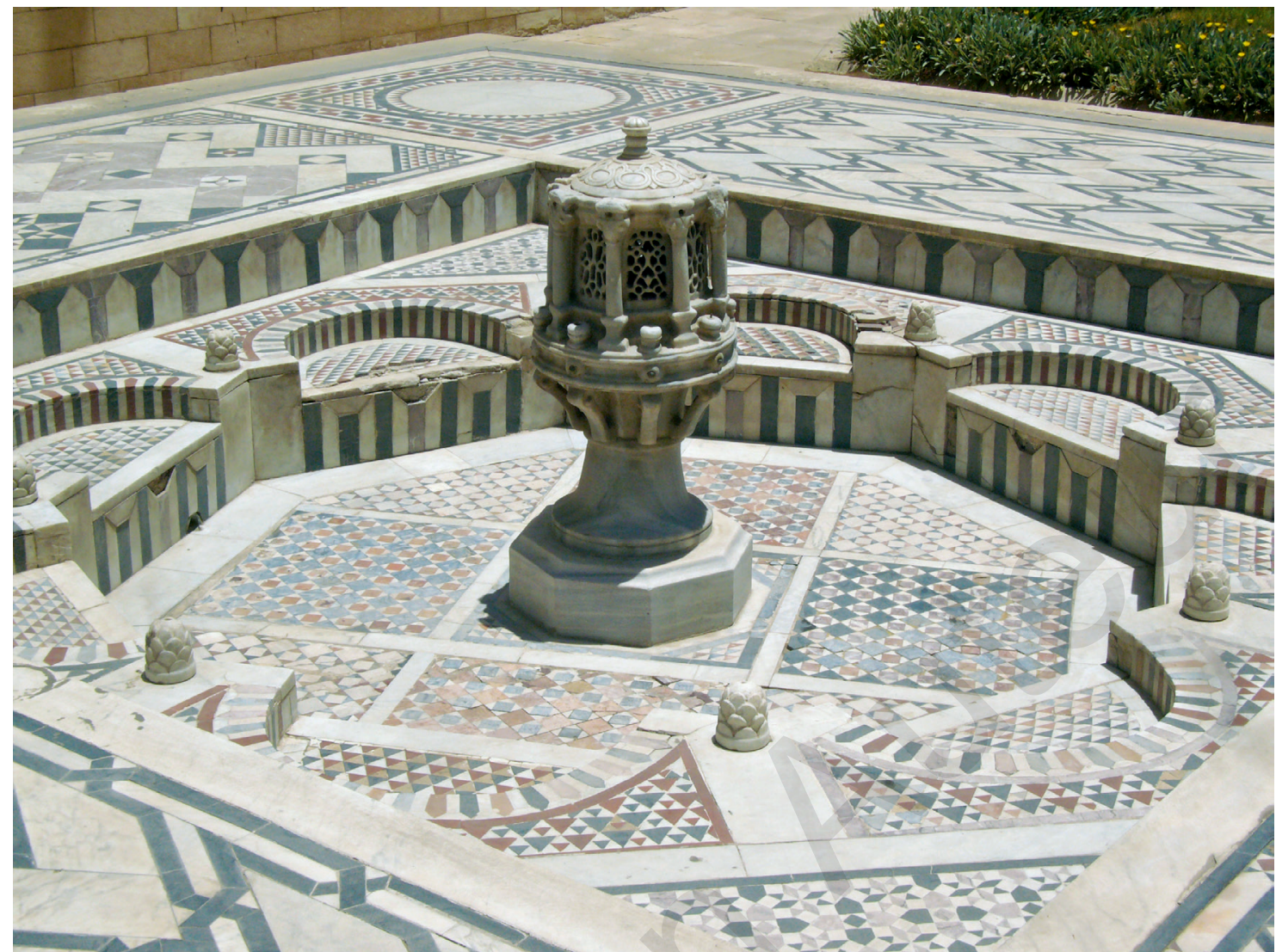

Fig. Io. Fasqiyya de la cour devant la façade néo-fatimide du Musée copte.

(c) Julien Auber de Lapierre, avec l'aimable autorisation du Musée copte.

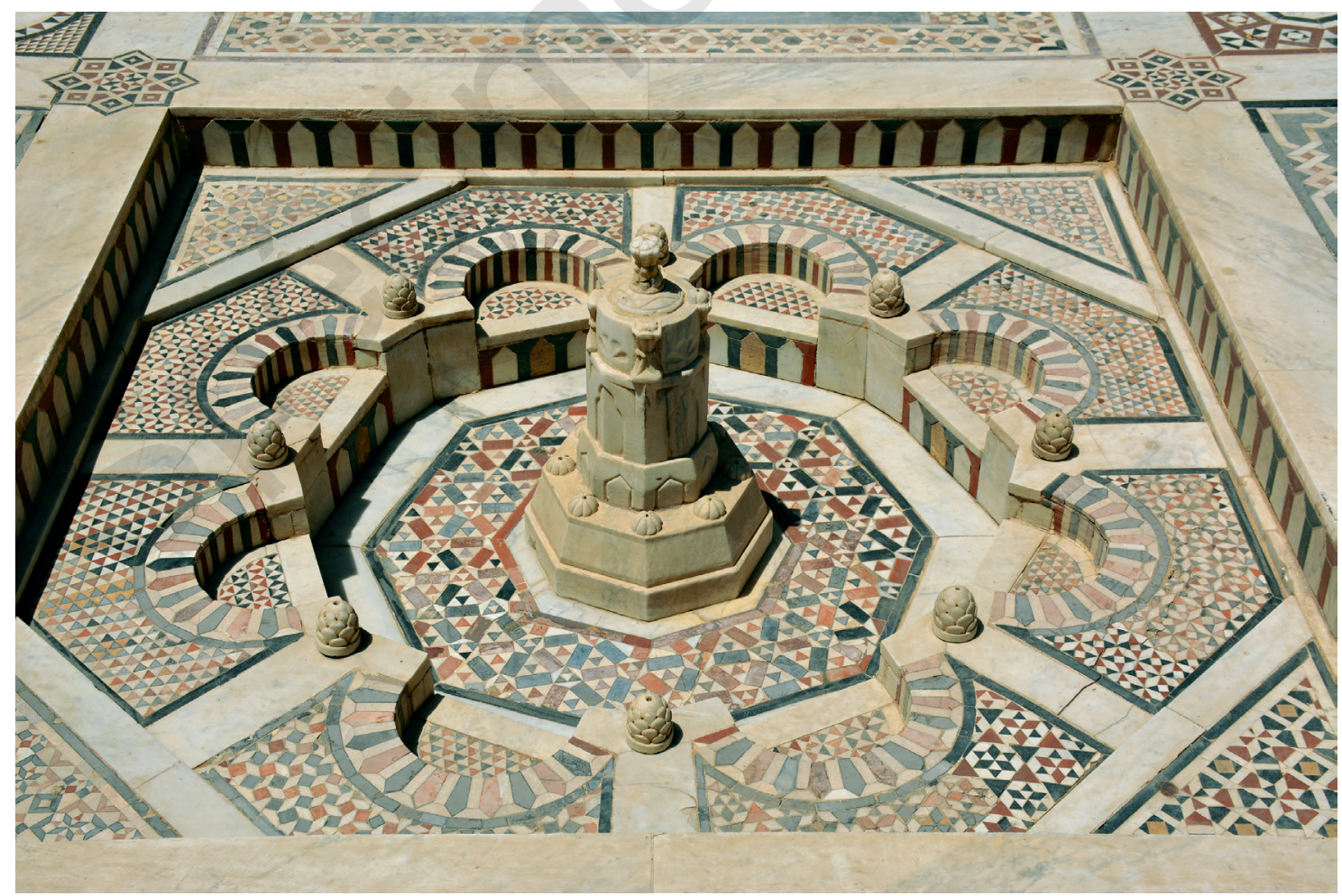

Fig. II. Fasqiyya de la cour devant la façade néo-fatimide du Musée copte.

(c) Julien Auber de Lapierre, avec l'aimable autorisation du Musée copte. 
wagf selon les conditions fixées, et peut ensuite en faire ce que bon lui semble, soit une habitation, soit un lieu de stockage. Le troisième manuscrit est un document de construction issu du tribunal du al-Bāb al- 'Ālì et daté de $1195 /$ I78I ${ }^{88}$. Il est fait mention d'une résidence donnant au sud sur un couvent, au nord sur le waqf de Mār Tādrus, à l'est sur l'église al- 'Aḍrā' ${ }^{89}$, et à l'ouest sur une impasse qui correspond à la façade de la maison. Des travaux de déblaiement et de construction ont été réalisés et sont l'occasion d'une description complète du palais, qui est identifié sous le nom de «nouvelle cellule». Sa façade est faite de pierres rouges avec une porte à pont-levis. Un couloir mène à une vaste cour ouverte, au centre de laquelle se trouve une fasqiyya de marbre. On trouve dans ce grand espace l'une des premières salles du salamlik entourée de bancs de bois et élevée de deux marches, le tabtabūšs, pourvu d'une colonne de marbre. Une porte mène ensuite à l'appartement du salamlik avec la mandara composée de deux ìwān-s. Au-dessus du tabtabüš se trouve une grande salle avec une grande fenêtre réalisée par un menuisier, qui donne sur la cour. À la droite de cette ouverture, un moucharabieh donne également sur la cour. La description se perd ensuite dans de nombreuses pièces, des escaliers et des accès menant au couvent. Enfin, la dernière source mise en avant par Magdi Guirguis est un document de waqf conservé aux Archives du Patriarcat copte orthodoxe, daté de l'année II95/I781 ${ }^{90}$. Reprenant la description qui avait été faite précédemment, il y est précisé que le patriarche - Yūhannā XVIII à cette époque - doit continuer à s'occuper du bâtiment et de son entretien. Les noms des frères Ibrāhīm et Ğirǧis al-Ǧawharī, membres influents de la communauté copte, apparaissent ensuite. Issus d'une famille pauvre, ils s'illustrèrent par de brillantes études. Ibrāhīm, mort en I795, est le plus influent des deux et se fait très vite remarquer par le patriarche Yūhannā XVIII ${ }^{91}$. Devenu secrétaire du múallim Rizq ${ }^{92}$, il fut nommé par le mamelouk Ibrahim Bey - qui faisait peu de cas des confessions - à un poste important dans l'administration des Finances. Usant de son influence politique et économique, il restaura de nombreux monastères et églises. Les autorisations étaient alors aisées à obtenir du fait de sa position. Actifs et généreux mécènes, les deux frères permirent de nombreuses donations, notamment de terrains à bâtir. C'est à ce titre qu' ils agrandirent la résidence du patriarche à Hārat al-Rūm.

La comparaison de ces documents et des descriptions particulièrement précises qu'ils présentent avec un tableau de John Frederick Lewis intitule Study for "The Courtyard of the Coptic Patriarch's House in Cairo" réalisé aux environs de 1864 , est riche de résultats ${ }^{93}$ (fig. I3). Dans cette ouvre représentant la maison où Lewis résida durant son séjour au Caire dans les

88. Tribunal du al-Bāb al- 'Âlī, registre $197, \mathrm{n}^{\circ}$ I43, p. IIO.

89. Il s'agit de l'église consacrée à la Vierge Marie se trouvant toujours dans le quartier de Ḥārat al-Rūm: Meinardus, 1999, p. 196.

90. Inv. D 463 .

91. Ludwig, 2013, p. 136.

92. Bureaucrate et administrateur financier, il est le fils du mu' allim 'Ațāllāh al-Nașrānī al-Ya' qūbì al-mubāšir: Guirguis, 2008, p. 73 .

93. John Frederick Lewis, Study for "The Courtyard of the Coptic Patriarch's House in Cairo", v. I864, Nor688, Londres, Tate. 


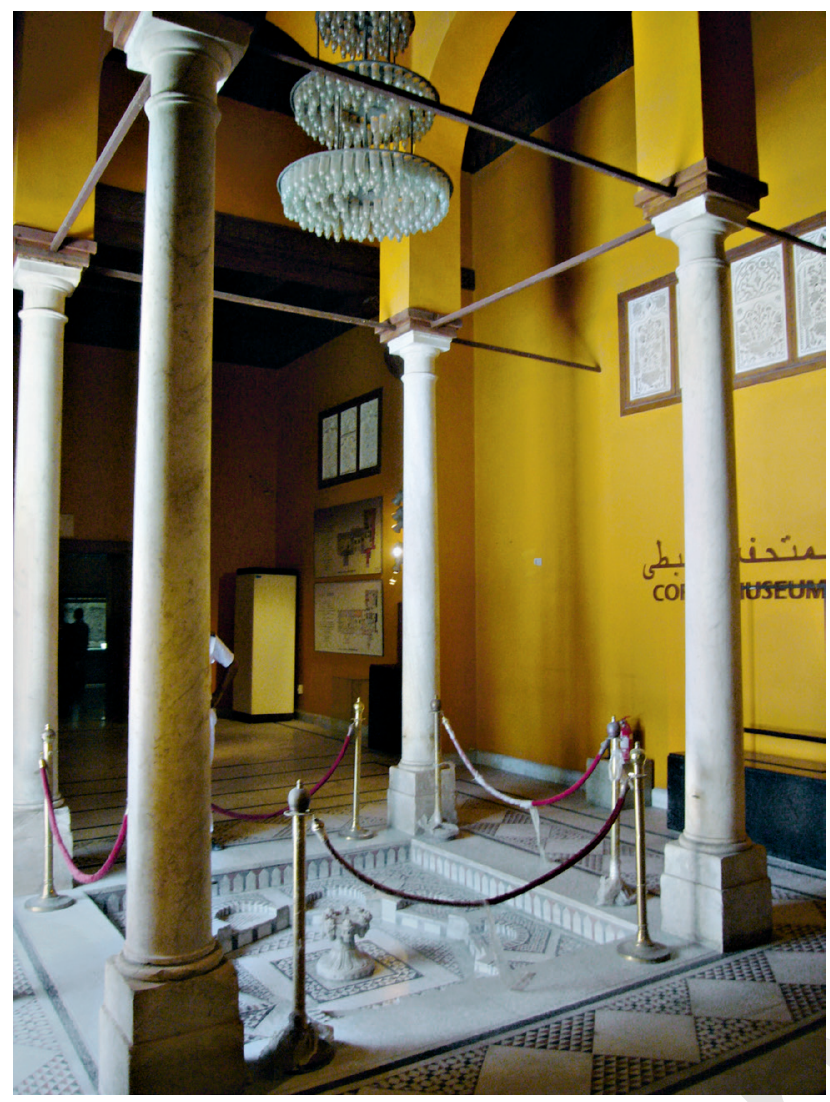

Fig. 12. Fasqiyya de la salle 25 du Musée copte. (C) Julien Auber de Lapierre, avec l'aimable autorisation du Musée copte.

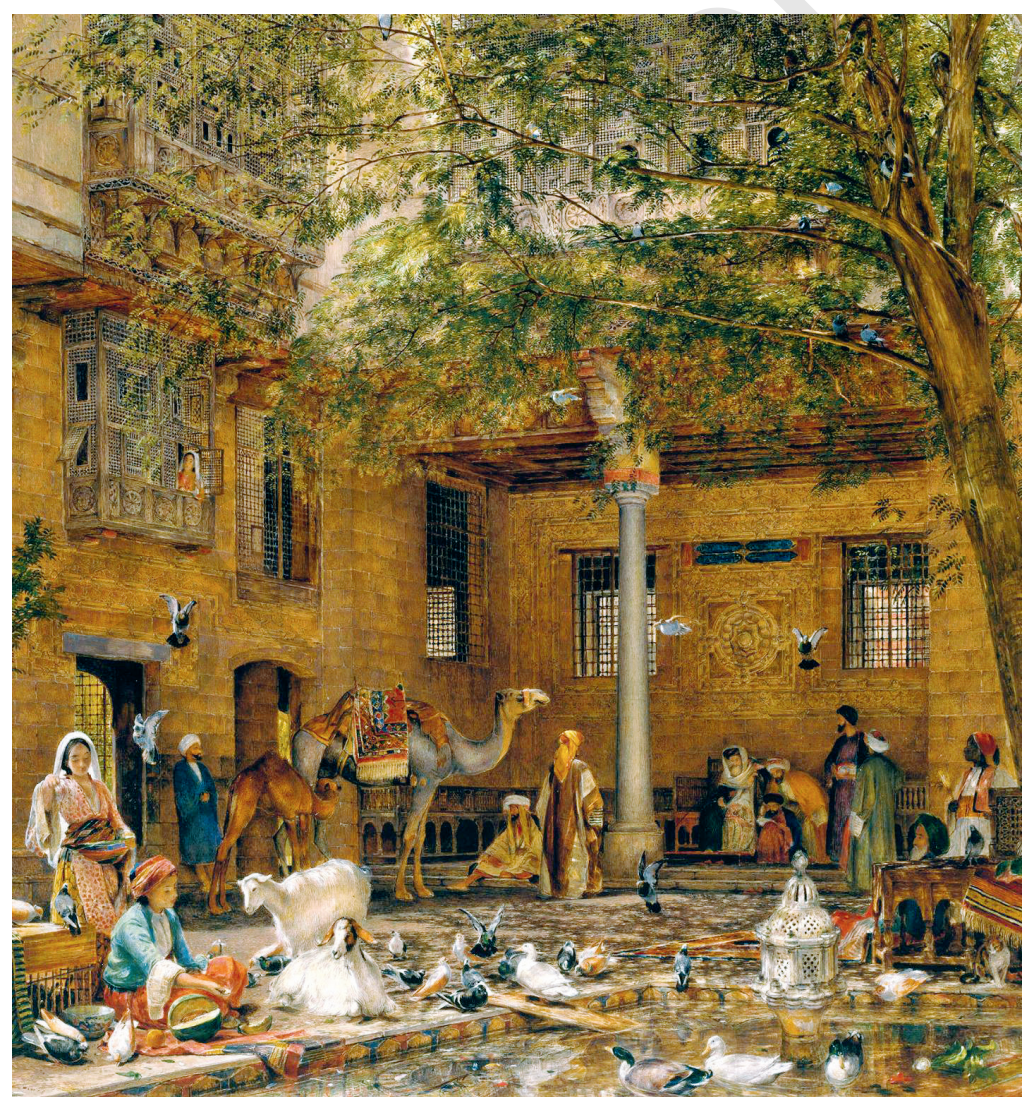

Fig. I3. John Frederick Lewis, Study for "The Courtyard of the Coptic Patriarch's House in Cairo", v. I864, huile sur bois, Nor688, Londres, Tate. (C) Tate, London, 2015 . 
années $1840^{94}$, le foisonnement de détails mêle observation de l'art islamique, coutumes évoquées par Edward William Lane ${ }^{95}$ et inspiration orientaliste. Le peintre représente une vaste cour arborée sur laquelle donne un tab̧tabūšs soutenu par une colonne de marbre blanc. Le patriarche copte y est assis avec un scribe, et parmi les personnages se trouve un dignitaire musulman. Autour de la fasqiyya située au centre de la cour, un garçon et une jeune fille semblent nourrir des animaux. Auprès d'eux, une véritable basse-cour constituée de canards, pigeons, chèvres et chat. Deux dromadaires sont également figurés avec des hommes près de deux portes, à gauche, menant aux appartements. Les façades sont, quant à elles, ornées de moucharabiehs à encorbellement richement ouvragés. Les recherches menées par Emily Weeks ont permis d'éliminer les quartiers européens du Caire où Lewis aurait pu résider durant son séjour ${ }^{96}$. Les dessins (dont un plan ${ }^{97}$ ) de cette maison réalisés par James William Wild semblent alors bien correspondre à quelques tableaux de Lewis, mais, comme le montre Emily Weeks, le travail tout orientaliste de l'artiste mêle astucieusement réalité et imaginaire ${ }^{98}$. Toutefois, la description très précise, fournie dans les documents mentionnés précédemment, de la cellule du patriarche de Hārat al-Rūm, abandonnée pour des raisons de sécurité depuis le départ des Français du Caire en I80I ${ }^{99}$, rend tentante l' hypothèse qu'il s'agit bien du même lieu. De plus, Lewis réalisa plusieurs œuvres à son retour en Angleterre célébrant ce palais, et les différents points de vue correspondent toujours avec la description historique donnée plus haut ${ }^{100}$. Le bon état relatif du palais, en ce milieu $\mathrm{du} \mathrm{XIX}^{\mathrm{e}}$ siècle, permettrait alors de comprendre, près d'un siècle après son abandon par le patriarche, la réutilisation de matériaux pour le Musée copte.

En effet, les nombreuses transformations de la ville du Caire entamées par le khédive Ismail Pacha(I863-1879) bouleversèrent l'urbanisme cairote et aboutirent à la destruction de nombreux édifices ${ }^{\text {IOI }}$. Parmi les antiquaires et amateurs de ce temps, la figure du comte Gaston de Saint-Maurice (I83I-I905) est à prendre à part. Passé maître dans l'art du remploi, le Grand Écuyer du khédive fait élever son hôtel particulier, entre I872 et I880, par les architectes Charles Guimbard et Marcel GouronBoisvert d'après les plans et dessins exécutés par Ambroise Baudry. Les plafonds, fontaines, lambris, pavements de mosaïque, boiseries, moucharabiehs étaient le fruit d'assemblages savants du patrimoine qu'il collectionnait ${ }^{102}$. Si cet hôtel n'existe plus en l'état dans le quartier d'Ismā îliyya, une grande partie de ses décors intérieurs se trouvent aujourd'hui à la chancellerie de France à Guiza ${ }^{103}$. Saint-Maurice vendit aussi les œuvres qu'il amassait, notamment au South Kensington Museum

94. Weeks, 2014, p. 40-42.

95. Lane, 2012, p. I32-I54.

96. Weeks, 2014, p. 39-52.

97. James William Wild, "Ground Plan. [... . /Mr. Lewis House/Cairo», Drawing showing the interior decoration of houses in Cairo, v. I840, E+3766-1938, Londres, Victoria \& Albert Museum.

98. Weeks, 2014, p. 63-70.

99. Guirguis, van Doorn-Harder, 2011, p. 62.

Ioo. Entre autres: John Frederick Lewis, Courtyard of the Painter's House, Cairo, I850-I851, I948P 44, Birmingham, Museum \& Art Gallery, et John Frederick Lewis, The Midday Meal, Cairo, I875, collection particulière.

IOI. Volait, 2009, p. I8I-I93.

I02. Volait, 2009, p. 90-99.

I03. Volait, 20I2. 
de Londres (futur Victoria \& Albert Museum) en I884. Parmi les pièces envoyées en France, une «porte d'entrée d'une ancienne maison arabe » attire l'attention. Ce qui est en réalité un porche était resté initialement sur le chantier des architectes de son hôtel particulier. Charles Guimbard annonce fin I 888 qu'il envisage de donner « cette pièce intéressante » au Musée arabe du Caire si son propriétaire ne l'en débarrasse pas. Vingt-cinq caisses sont expédiées à Paris en I889 ${ }^{104}$, car Saint-Maurice a bon espoir de pouvoir vendre le porche à l'Union centrale des arts décoratifs, laquelle en refuse néanmoins l'acquisition faute de moyens ${ }^{105}$. Le décès en 1905 de Gaston de Saint-Maurice laisse l'affaire en suspens, et les caisses en déshérence, jusquà leur redécouverte récente ${ }^{106}$. Mais au-delà de l'intérêt architectural majeur de cette pièce que l'on peut désormais découvrir au département des Arts de l'Islam du musée du Louvre ${ }^{107}$, ćest l'annotation que Jules Bourgoin a laissée sur plusieurs dessins, «Kasr Roumy», qui attire l'attention ${ }^{108}$. Comme nous avons pu le voir précédemment, la cellule patriarcale du quartier de Hārat al-Rūm trouve ses origines architecturales à l'époque mamelouke. Malheureusement, et même si l'hypothèse peut paraître séduisante, aucun élément dans les sources dépouillées entre la première mention du porche au Caire et son arrivée à Paris ne permet de le relier directement à la résidence du patriarche. Toutefois, il serait étonnant que seules les fontaines et les boiseries aient été remployées pour l'usage du Musée copte. Démantelés selon toute vraisemblance entre I 874 et I $889^{109}$, les 339 blocs de calcaire bichrome conservés au musée du Louvre pourraient être alors l'un des rares témoignages du bâtiment.

Les remplois sont particulièrement nombreux dans l'architecture du Musée copte. Au-delà des deux fasqiyya-s se trouvant dans la cour devant l'entrée actuelle, de celle se trouvant dans la salle dont la façade est inspirée de la mosquée al-Aqmar, et enfin de celle qui se trouve dans la bibliothèque, toutes datables de l'époque mamelouke, il convient d'ajouter les crédences (suffa) incrustées de marbres polychromes (fig. I4). Ces dernières présentent, pour certaines, des carreaux de céramique provenant d'Iznik ou de Kütahya décorés de croix. Certaines proviendraient d'ailleurs du palais de Ǧirğis al-Ǧawharī dans le quartier de l'Azbakiyya ${ }^{\text {IIo. }}$. Des exemples de carreaux de céramiques à décor floral sur fond vert ayant survécu à l'hôtel de Saint-Maurice et aujourd'hui remontés à la Chancellerie de l'ambassade de France en Égypte

I04. Lettre du directeur général des douanes au secrétaire général de l'Union centrale des arts décoratifs, le 27 mars 1889 (Paris, Archives de la Bibliothèque des Arts décoratifs, Ci/45, Dossier de la commission du musée «Porte arabe»).

105. Note de L. Metman à Saint-Maurice à propos du porche et de sa collection, Archives de la Bibliothèque des Arts décoratifs, $\mathrm{CI} / 53$, dossier «Acquisitions et propositions d'acquisitions I898-1902».

I06. Daskalakis Mathews, 2012, p. 6-9, qui parle d'un don, sur la base d'une documentation fragmentaire. 107. Inventaire AD RI 2003/26-I; Daskalakis Mathews, 20I2. Nous remercions très sincèrement Yannick Lintz, directrice du département des Arts de l'Islam, de nous avoir permis de consulter le dossier relatif au porche mamelouk.

I08. Une partie des dessins est conservée à la Bibliothèque de l'École des beaux-arts à Paris (EBA 7900, f. II, I84, 318, 624-625, 638), et l'autre à la Bibliothèque de l'INHA - collections Jacques-Doucet, Archives 067 , I3, OI, sous-dossier de I2 f. Nous remercions chaleureusement Mercedes Volait, directrice du laboratoire InVisu, pour nous avoir communiqué les références de la documentation disponible.

109. Volait, 2012, p. 54.

I Io. Simaïka, I930, p. 33 . 
sont d'ailleurs identiques à ceux présentés au Musée copte ${ }^{\mathrm{III}}$. Ils ornent la partie supérieure d'une șuffa conservée dans la salle consacrée aux trésors d'églises.

Déjà évoquées précédemment dans la description de la résidence et dans le tableau de Lewis, les structures de bois de type moucharabieh ont fait l'objet d'un soin particulier par Marcus Simaïka Pacha. Issues de Hārat al-Rūm ${ }^{\mathrm{II} 2}$ et de différents palais démantelés ayant appartenu à des chrétiens ${ }^{\mathrm{II}}$, elles ont été, pour la plupart, soigneusement remontées sur les vastes baies de l' "ancienne aile » ${ }^{\mathrm{I} 4}$ (fig. I5). Sauvées des flammes qui les guettaient, elles furent même trop nombreuses. Inventoriées dans les collections, certaines sont ainsi aujourd'hui abandonnées, dans un piètre état, dans la réserve externalisée du Musée copte se situant à Fustat $^{\mathrm{II}}$. Leurs décors, dans les parties supérieures, figurent des vases de fleurs, des croix ou des passages des psaumes. Certaines sont également ornées de vitraux colorés.

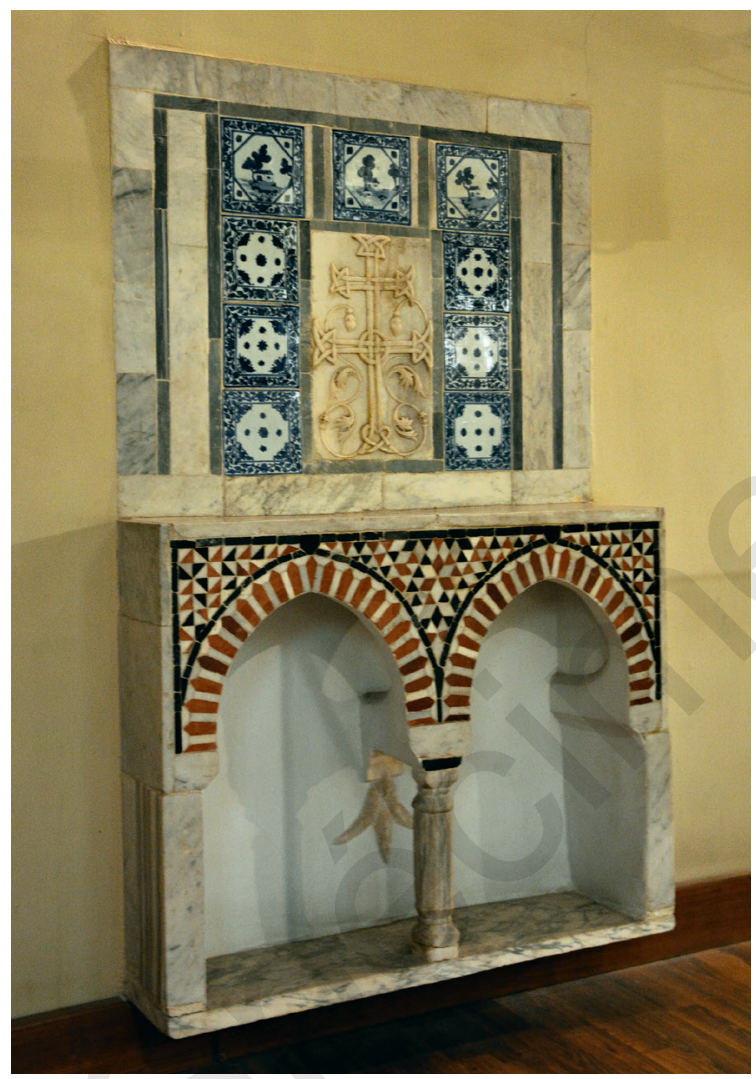

Fig. 14. Șuffa, Musée copte.

(C) Julien Auber de Lapierre, avec l'aimable autorisation du Musée copte.

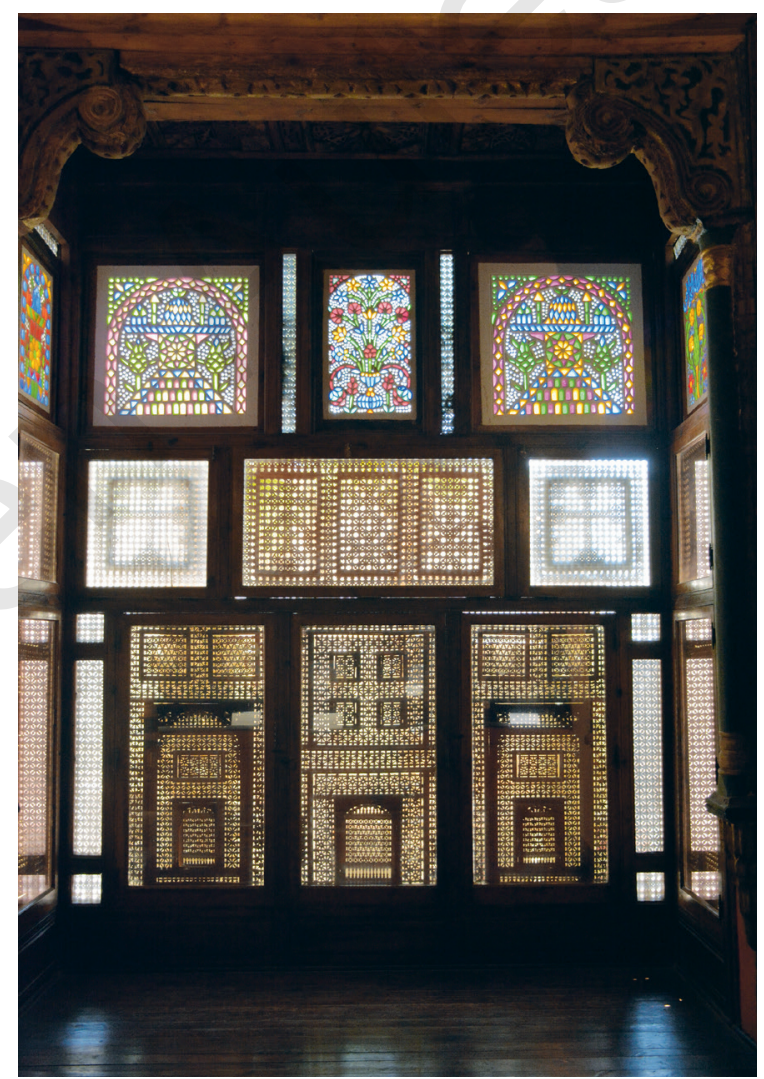

Fig. 15. Moucharabieh de la salle I7 du Musée copte (vue intérieure).

(C) Julien Auber de Lapierre, avec l'aimable autorisation du Musée copte.

I I I. Volait, 20I2, p. 239, fig. I79.

I 12. Un très bel exemplaire a été dessiné par John Frederick Lewis : Courtyard of the Painter's house. Cairo, V+ I840, inv+ 287-I898, Londres, Victoria \& Albert Museum.

I I3. Simaika, 20II, p. 97 .

I I4. Le moucharabieh de la salle 17 provient de la cellule patriarcale de Hārat al-Rūm et est décrit par Simaïka comme étant «l'une des plus belles d’Égypte», Simaïka, I930, p. I22. Il y est toujours en place.

I 15. Auber de Lapierre, Vanderheyden, 2016, p. I537-I538. 
Les éléments les plus remarquables dans cet assemblage hétéroclite sont sans doute les plafonds. Parmi ceux-ci, celui de la salle Mounira située au premier étage est le plus spectaculaire ${ }^{\mathrm{II} 6}$ (fig. 16 et I7). Cette salle tient son nom de Mounira Daoud, fille de feu Daoud Bey Takla, qui offrit la somme de 500 livres égyptiennes en 1920 pour les travaux de cette salle. Les moucharabiehs qui ornent les baies ont été offerts par les héritiers de Shenouda Bey Bakhoum ${ }^{\text {II7 }}$ (fig. 18). La structure du plafond, dont le dessin a été tracé la même année par Tavarelli, présente une construction rectangulaire tripartite, organisée autour d'un lanterneau central sculpté de muqarnas ${ }^{118}$. Le tambour est percé de fenêtres ornées de vitraux colorés. La voûte, étagée sur trois registres, est peinte de motifs floraux et de scènes côtières constituées de villages et de bateaux. La partie inférieure est ornée d'un registre de muqarnas. Sur des variantes or, jaune et bleu, cette composition est caractéristique de la peinture ottomane du XviII ${ }^{e}$ siècle. Les bords de la structure sont parcourus de motifs d'étoiles organisés autour de coupolettes.

L'usage abondant de remplois au Musée copte tend à créer une confusion entre contenant et contenu. L'originalité de ce musée tient-elle à la plus grande réunion d'objets liés à la communauté chrétienne en Égypte ou à la célébration d'un bâtiment vantant les revendications d'une minorité?

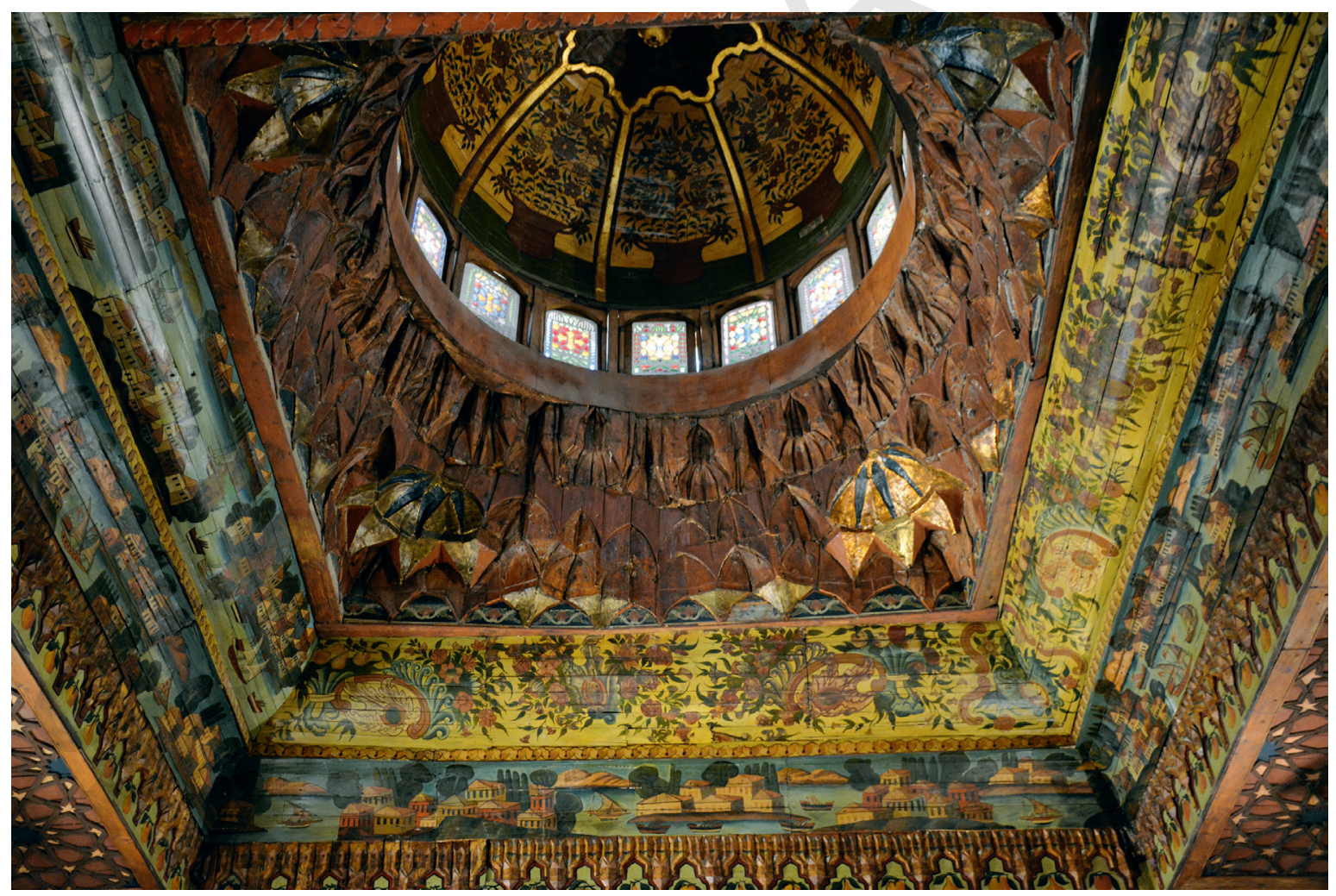

Fig. 16. Plafond de la salle Mounira (détail de la coupole centrale), xviri siècle, Musée copte.

(C) Julien Auber de Lapierre, avec l'aimable autorisation du Musée copte.

I I6. Il s'agit des salles 22 et 23 du plan de I937, actuelles salles i 8 et I9.

I 17. Simaïka, I930, p. 89 .

I I8. Inv. Monuments coptes $\mathrm{n}^{\circ}$ 242, 8 mars I920. 


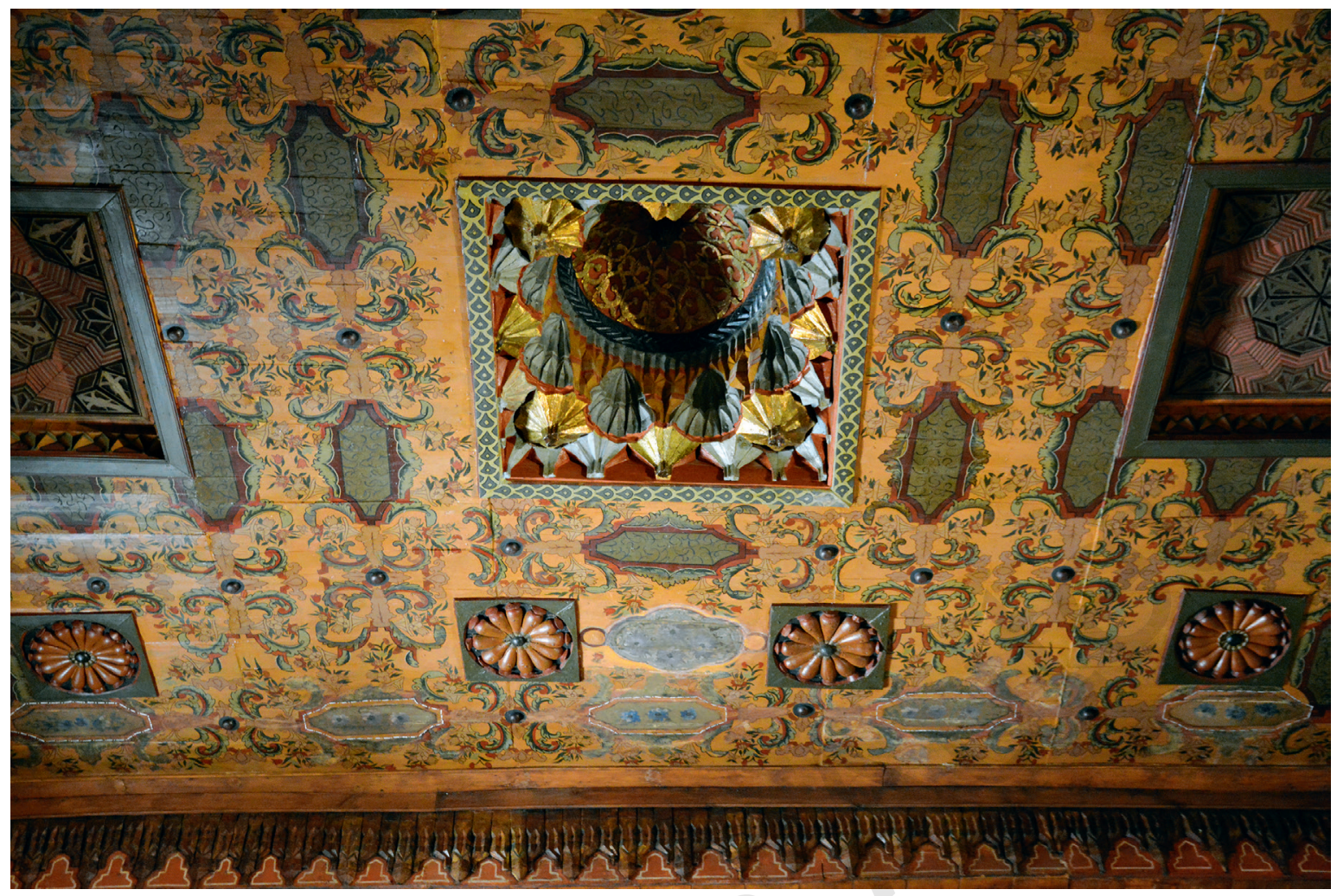

Fig. I7. Plafond de la salle Mounira (détail), $\mathrm{xvirI}^{\mathrm{e}}$ siècle, Musée copte.

(C) Julien Auber de Lapierre, avec l'aimable autorisation du Musée copte.

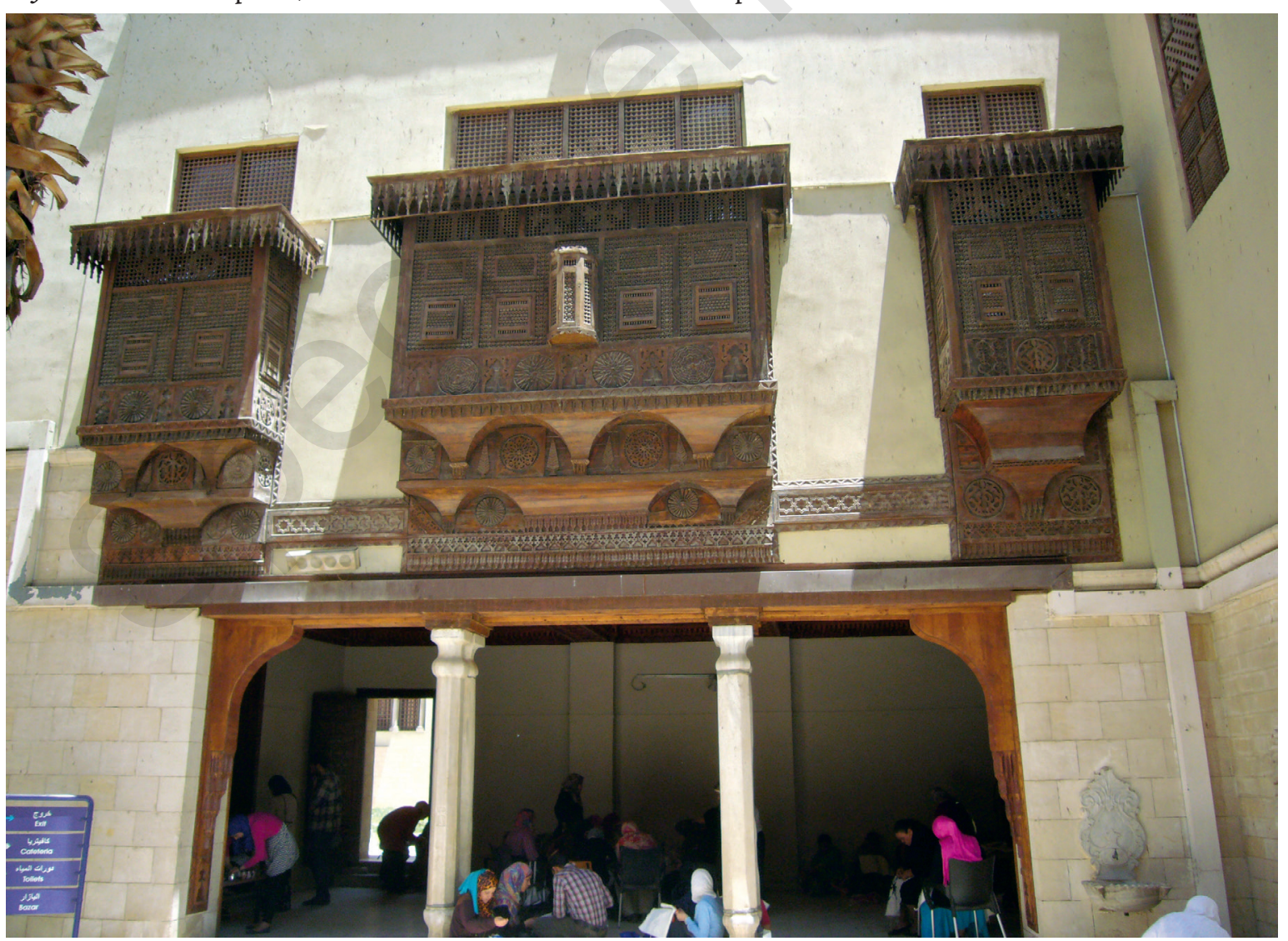

Fig. I 8. Moucharabiehs de la salle Mounira du Musée copte (vue extérieure).

(C) Julien Auber de Lapierre, avec l'aimable autorisation du Musée copte. 
Cette étude préliminaire consacrée à l'architecture du Musée copte permet de mettre en relief les bouleversements que connaît la communauté chrétienne d'Égypte entre la seconde moitié $\mathrm{du} \mathrm{XIX}{ }^{e}$ siècle et la première moitié $d u \mathrm{Xx}^{\mathrm{e}}$ siècle. Très longtemps mise à l'écart par le pouvoir ottoman, cette minorité retrouve pleinement ses droits avec le vice-roi Mohammed Saïd Pacha (1854-1863) et développe alors le besoin de se trouver une identité. Puisant dans les racines pharaoniques, la reconnaissance d'un patrimoine copte contribue à cette construction identitaire. Le développement de la notion $\mathrm{d}^{\prime}$ «art copte» contribue à forger une revendication patrimoniale qui sexprime avec le musée. Initié par le Comité de conservation des monuments de l'art arabe, le Musée copte est instrumentalisé par Marcus Simaïka Pacha afin de construire un passé et surtout un avenir à la communauté. Il le voit alors comme l'aboutissement d'une reconnaissance. L'utilisation d'une ancienne résidence patriarcale, les statuts de droit privé, les remplois, marquent la revendication d'un style copte, voire d'une Égypte copte. Le directeur et les architectes puisent dans ce qu'ils pensent être un vocabulaire architectural chrétien recyclé par l'Islam, afin d'ancrer l'identité copte en contribuant à démontrer l'enracinement des chrétiens de la vallée du Nil dans la culture fatimide, mamelouke et ottomane.

La patrimonialisation matérielle et immatérielle du Musée copte exprime les tensions qui ont existé à cette période entre le Comité, le patriarche et le roi. La volonté de ce dernier de se réapproprier l'institution met en avant les tensions politiques qui ont pu exister autour de la construction nationale que connaissait alors l'Égypte.

Alors que les pièces de l'époque byzantine sont minoritaires parmi les œuvres conservées, le musée serait plutôt consacré en définitive à l'art islamo-chrétien. La façade, inspirée de la mosquée al-Aqmar, de même que les remplois issus de palais mamelouks et ottomans, viennent compléter et célébrer cette source artistique inépuisable qu'est l'Égypte. Pourtant, au-delà de ce bric-à-brac, c'est l'étonnante synthèse de la vision du patrimoine égyptien que l'on observe dans ce musée. Les apports des archives permettent surtout de prendre conscience de la complexité de ce bâtiment. Au-delà des réflexions des architectes sur le sens à donner au musée, et au-delà des interrogations communautaires, voire communautaristes, le Musée copte est un creuset des arts qui ont construit l'identité de l'Égypte, alliant les différents pouvoirs et les différentes religions qui s'y sont succédé. Ces nombreux remplois contribuent à mettre en valeur l'émergence d'une communauté, d'une «culture copte» qui tente de retrouver ses racines en terre d'islam. 


\section{Bibliographie}

\section{Abréviations bibliographiques}

AnIsl: Annales islamologiques.

ARCE: American Research Center in Egypt.

ASAE: Annales du Service des Antiquités de l'Égypte.

BSAC: Bulletin de la Société d'archéologie copte, Le Caire.

$\mathrm{CBC}$ : Cahiers de la Bibliothèque copte.

CME : Evetts, B.T.A. \& Butler, A.J. (éd.), The Churches and Monasteries of Egypt and Some
Neigbbouring Countries Attributed to Abû Sâlih, the Armenian, Clarendon Press, Oxford, I895.

CCMAA: Comité de conservation des monuments de l'art arabe, Le Caire.

EtudAlex: Études alexandrines.

OLA: Orientalia lovaniensia analecta.

$\mathrm{SKCO}$ : Sprachen und Kulturen des Christlichen Orients.

\section{Sources graphiques (par ordre chronologique)}

Les documents sont conservés au Markaz tasğìl al-ātāàr al-islāmiyya wa-l-qibțiyya (Centre d'enregistrement des monuments islamiques et coptes du ministère des Antiquités situé dans la Citadelle du Caire).

«Relevé fait de l'annexe de l'église el-Moallaka pour le projet du Musée copte », par M. Muller Ing,, Inv. Monuments coptes $\mathrm{n}^{\circ} 55$, plan $\mathrm{n}^{\circ} 5 \mathrm{I} 8$, I5 juin I9I2.

«Projet d'un musée pour les Antiquités coptes au nord de l'église el-Moallaka au Vieux-Caire, Façade principale donnant sur le jardin », par M. Steyrer, Inv. Monuments coptes $n^{\circ} 58$, plan $n^{\circ} 547,30$ mars 1913.

«Projet d'un musée pour les Antiquités coptes au nord de l'église el-Moallaka au Vieux-Caire», visé par Max Herz, Inv. Monuments coptes no 57 , plan $n^{\circ} 545$, 3I mars 19I3.

«Projet de coupole», Inv. Monuments coptes $n^{\circ} 63$, non daté.

«Design of the facade», Inv. Monuments coptes $n^{\circ} 68$, non daté.

«Projet d'un musée pour les Antiquités coptes au nord de l'église el-Moallaka au Vieux-Caire coupe $A-B »$, par M. Steyrer, plan no 546, 31 mars 1913.

«Escalier extérieur», par Giuseppe Tavarelli et Gaston Rossi, Inv. Monuments coptes $n^{\circ} 69$, avril 1917.

«Fontaine pour le jardin du Musée copte», par Gaston Rossi, visé par Achille Patricolo, plan $\mathrm{n}^{\mathrm{o}} 2883$, Inv. Monuments coptes $\mathrm{n}^{\circ} 72,30$ octobre 1917.
«Musée copte. Rampe de l'escalier extérieur», et "détail en grandeur des pommes de pin», par M. Tavarelli, visé par Achille Patricolo, Inv. Monuments coptes $\mathrm{n}^{\circ}$ 70, 25 avril 1918.

"Musée copte du Vieux-Caire. Façade», par Giuseppe Tavarelli, visé par Achille Patricolo, Inv. Monuments coptes $n^{\circ} 231,3$ octobre 1918.

«Musée copte du Vieux-Caire. Nouveau taktaboche. Plafonds », par Giuseppe Tavarelli, Inv. Monuments coptes $\mathrm{n}^{\circ}$ 242, 8 mars 1920.

«Musée copte. Dessin pour le jardin», par Gaston Rossi, Inv. Monuments coptes n ${ }^{\circ}$ 246, I5 mai 1920.

«Nouvelle moucharabieh sur la façade Nord Est », par Giuseppe Tavarelli, visé par Achille Patricolo, Inv. Monuments coptes $n^{\circ} 249$, I5 novembre 1920 .

«Musée copte. Complément de la façade nord. Type des fenêtres », par Gaston Rossi, Inv. Monuments coptes $n^{\circ} 267,5$ juillet 1922 .

«Musée copte. Façade ouest. Détail de la loggia», par G. Rossi, Inv. Monuments coptes $n^{\circ} 268$, 24 juillet 1922.

«Nouveau takhtaboche, fenêtre du I ${ }^{\text {er }}$ étage et châssis des fenêtres », visé par Achille Patricolo, Inv. Monuments coptes $n^{\circ} 237$, non daté. 


\section{Sources imprimées}

Butler, Alfred Joshua, The Ancient Coptic Churches of Egypt, 2 vol., The Clarendon Press, Oxford, 1884.

Clédat, Jean, Le monastère et la nécropole de Baouitt, MIFAO I2, Ifao, Le Caire, 1904.

Crum, Walter Ewing, Catalogue général des antiquités égyptiennes du musée du Caire, ( $N^{o s}$ 8001-8741): Coptic Monuments, Ifao, Le Caire, 1902.

Crum, Walter Ewing, L'art copte: école d'Alexandrie, architecture monastique, sculpture, peinture, art somptuaire, Ernest Leroux, Paris, 1902.

Gayet, Albert, Les monuments coptes du musée de Boulaq, Ernest Leroux, Paris, I889.

Georg, Johann, Streifzüge durch die Kirchen und Klöster Ägyptens, Druck und Verlag B.G. Teubner, Berlin, 1914.

Lane, Edward William, An Account of the Manners and Customs of the Modern Egyptians,

The Definitive i860 Edition, The American University in Cairo Press, Le Caire, 2012.

«Lettre lue le 4 janvier I898 devant l'assemblée du Comité de conservation des monuments de l'art arabe et rapportée au procès-verbal $\mathrm{n}^{\circ} 80$ », CCMAA I5, p. 4-6.

Prisse d'Avennes, Émile, L'art arabe d'après les monuments du Kaire, depuis le viI siècle jusqu'à la fin $d u X_{\text {XVIII }}^{e}$. Texte, A. Morel et $\mathrm{C}^{\mathrm{ie}}$, Paris, I877.

\section{Études}

Auber de Lapierre, Julien, «Tradition et innovation La dualité iconographique du peintre Yuhanna al-Armani » in Boud'hors, Anne \& Louis, Catherine, Études coptes XIII, Quinzième journée d'études (Louvain-la-Neuve, 12-14 mai 2011), CBC 20, De Boccard, Paris, 2015, p. 27-42.

Auber de Lapierre, Julien \& Jeudy, Adeline, Catalogue général du Musée copte du Caire - Objets en bois I, Ifao, Le Caire, à paraître.

Auber de Lapierre, Julien \& Vanderheyden, Loreleï, "The "Simaïka-Pacha" Association: Salvaging a Forgotten Storage Unit of the Coptic Museum, Cairo » in Camplani, Alberto \& Buzi, Paola (éd.), Proceedings of the Tenth International Congress of Coptic Studies (Rome, September 17-22, 2012), OLA 247, Peeters, Louvain, 2016, p. 1535-1544.
Quibell, James Edward, «Kom Ishgau», $A S A E$ 3, 1902, p. 85-88.

Simaïka, Marcus H., Note historique sur le Musée copte au Vieux Caire à l'occasion de la visite de Sa Hautesse Fouad I ${ }^{\text {er }}$, Sultan d'Égypte, Mardi, 21 décembre 1920, Mațba'at al-Ma'ārif, Le Caire, 1920.

Simaïka, Marcus H., Dalil al-mathaf al-qibți wa ahamm al-kanā' is wa-l-adyura al-atariyya, Imprimerie nationale, Le Caire, I930.

Simaïka, Marcus H., Guide sommaire du Musée copte et des principales églises du Caire, Imprimerie nationale, Le Caire, 1937.

Simaikka, Marcus H., A Brief Guide to the Coptic Museum and the Principal Ancient Churches of Cairo, Government Press, Le Caire, 1938.

Simaïka, Marcus H., Mémoires, Le Caire, s.d.

Strzygowski, Josef, Koptische Kunst, Catalogue général des Antiquités égyptiennes du musée du Caire $\mathrm{N}^{\mathrm{os}}$ 7001-7394 et 8742-9200, Imprimerie Adolf Holzhausen, Vienne, 1904.

Vansleb, Johann Michael, Nouvelle relation en forme de journal, d'un voyage fait en Égypte par le P. Vansleb en 1672 \& 1673, Estienne Michallet, Paris, 1677.
Behrens-Abouseif, Doris, Islamic Architecture in Cairo - An Introduction, The American University in Cairo Press, Le Caire, New York, 1989.

Boutros, Ramez Wadie, «La symbolique de la conque dans l'Égypte chrétienne et musulmane», Le Monde copte 20, 1992, p. 8I-87.

Coquin, Charalambia, Les édifices chrétiens $d u$ Vieux-Caire, vol. I, BEC II, Ifao, Le Caire, 1974.

Coquin, René-Georges, «Patriarcal Residences» in Atiya, Aziz Suryal (éd.), The Coptic Encyclopedia VI, I99I, p. 1912-I913.

Daskalakis Mathews, Annie-Christine, Le porche mamlouk, Solo 55, musée du Louvre, Somogy éditions d'art, Paris, 2012.

Den Heijer, Johannes, «Le patriarcat copte d'Alexandrie à l'époque fatimide » in Décobert, Christian (éd.), Alexandrie médiévale 2, EtudAlex 8, Ifao, Le Caire, 2002, p. 83-97. 
Edwards, Jill (éd.), Max Herz Pasha (1856-1919): His Life and Career, 2 vol, EtudUrb 6, Ifao, Le Caire, 2009.

Gabra, Gawdat \& Eaton-Krauss, Marianne, The Treasures of Coptic Art in the Coptic Museum and Churches of Old Cairo, The American University in Cairo Press, Le Caire, New York, 2006.

Godoli, Ezio \& Giacomelli, Milva (éd.), Architetti e ingegneri italiani dal Levante al Magreb: 1848-1945, Maschietto editore, Florence, 2005.

Gravit, Francis W., «Peiresc et les études coptes en France au XVII ${ }^{\mathrm{e}}$ siècle», BSAC 4, I938, p. I-22.

Guirguis, Laure, Les coptes d'Égypte. Violences communautaires et transformations politiques (2005-2012), Karthala, Paris, 2012.

Guirguis, Magdi, An Armenian Artist in Ottoman Egypt: Yubanna al-Armani and His Coptic Icons, The American University in Cairo Press, Le Caire, 2008.

Guirguis, Magdi, «Nuṣūṣ ğadīda ḥawla al-qalāyya al-bațriyarkiyya bi-Ḥārat al-Rūm », AnIsl 48, 2, 2015, p. I9I-2I5.

Guirguis, Magdi \& van Doorn-Harder, Nelly, The Emergence of the Modern Coptic Papacy, The American University in Cairo Press, Le Caire, 20II.

Hautecœur, Louis \& Wiet, Gaston, Les mosquées du Caire, Ernest Leroux, Paris, 1932.

Loon, Gertrud J.M. van, «The Christian Heritage of Old Cairo » in Ludwig, Carolyn \& Jackson, Morris (éd.), The History and Religious Heritage of Old Cairo: Its Fortress, Churches, Synagogue, and Mosque, The American University in Cairo Press, Le Caire, 2013, p. 72-243.

Ludwig, Carolyn \& Jackson, Morris (éd.), The History and Religious Heritage of Old Cairo: Its Fortress, Churches, Synagogue, and Mosque, The American University in Cairo Press, Le Caire, 20I3.

Martin, Maurice, «Alexandrie chrétienne à la fin du XII siècle d'après Abû l-Makârim » in Décobert, Christian \& Empereur, Jean-Yves (éd.), Alexandrie médiévale I, EtudAlex 3, Ifao, Le Caire, 1998, p. 45-49.

Meinardus, Otto F.A., Two Thousand Years of Coptic Christianity, The American University in Cairo Press, Le Caire, 1999.

O'Kane, Bernard, The Mosques of Egypt, The American University in Cairo Press, Le Caire, 2016.
Ormos, István, «Preservation and Restoration: The Methods of Max Herz Pasha, Chief Architect of the Comité de Conservation des Monuments de l'Art Arabe, 1890-1914 » in Edwards, Jill (éd.), Historians in Cairo, Essays in Honor of George Scanlon, The American University in Cairo Press, Le Caire, 2002, p. I23-I53.

Reid, Donald Malcolm, «Archeology, Social Reform, and Modern Identity Among the Copts (I854-1952) » in Roussillon, Alain (éd.), Entre réforme sociale et mouvement national, CEDEJ, Le Caire, 1995, p. 3II-335.

Reiss, Wolfram, Erneuerung in der KoptischOrthodoxen Kirche: Die Geschichte der koptisch-orthodoxen Sonntagsschulbewegung und die Aufnabme ibrer Reformansätze in den Erneuerungsbewegungen der KoptischOrthodoxen Kirche der Gegenwart, Studien zur orientalischen Kirchengeschichte 5, Lit Verlag, Münster, I998.

Rutschowscaya, Marie-Hélène, "Conques et tympans du musée du Louvre » in Krause, Martin \& Schaten, Sofia (éd.), Themelia, Spätantike und koptologische Studien: Peter Grossmann zum 65. Geburtstag, $\mathrm{SKCO}_{3}$, Reichert Verlag, Wiesbaden, 1998, p. 289-303.

Sanders, Paula, Creating Medieval Cairo: Empire, Religion, and Architectural Preservation in Nineteenth-Century Egypt, The American University in Cairo Press, Le Caire, 2008. Sheehan, Peter, Babylon of Egypt: The Archaeology of Old Cairo and the Origins of the City, ARCE Conservation Series 4, The American Research Center in Egypt, The American University in Cairo Press, Le Caire, New York, 2010.

Simaika, Samir Mahfuz, Marcus Pasha Simaika, Founder of the Coptic Museum: His Life and Times, Farid Atiya Press, Giza, 20II.

Voile, Brigitte, Les coptes d'Égypte sous Nasser. Sainteté, miracles, apparitions, Moyen-Orient, CNRS éditions, Paris, 2004.

Volait, Mercedes, «La tradition revisitée: réflexions sur un thème récurrent de la production architecturale européenne en Égypte » in Atti del Convegno "Architettura e architetti italiani ad Istanbul tra il XIX e il XX secolo», Istanbul, 27-28 novembre 1995, Istanbul, 1997, p. I09-116.

Volait, Mercedes, Fous du Caire: excentriques, architectes E amateurs d'art en Égypte (1863-1914), L'Archange Minotaure, Montpellier, 2009. 
Volait, Mercedes, Maisons de France au Caire Le remploi de grands décors mamelouks et ottomans dans une architecture moderne,

BiGen 44, Ifao, Le Caire, 2012.

Wahab, Hassan Abdel, «Marcus Simaika Pacha», BSAC 12, 1946-1947, Le Caire, 1949, p. 160-162.

Warner, Nicholas, The Monuments of Historic Cairo: A Map and Descriptive Catalogue, The American University in Cairo Press, Le Caire, 2005.
Weeks, Emily M., Cultures Crossed: John Frederick Lewis and the Art of Orientalism, Yale University Press, Londres, New Haven, 2014.

Williams, Caroline, "The Cult of 'Alid Saints in the Fatimid Monuments of Cairo. Part I: The Mosque of al-Aqmar », Muqarnas I, 1983, p. 37-52. 